\title{
Metal losses in pyrometallurgical operations - a review
}

\author{
$\underline{\text { Inge Bellemans }}{ }^{1}$, Evelien De Wilde ${ }^{12}$, Nele Moelans ${ }^{3}$, Kim Verbeken ${ }^{1}$ \\ 1: $\quad$ Ghent University - Department of Materials, Textiles and Chemical engineering \\ Technologiepark 903

\begin{abstract}
Nowadays, a higher demand on a lot of metals exists, but the quantity and purity of the ores decreases. The amount of scrap, on the other hand, increases and thus, recycling becomes more important. Besides recycling, it is also necessary to improve and optimize existing processes in extractive and recycling metallurgy. One of the main difficulties of the overall-plant recovery are metal losses in slags, in both primary and secondary metal production. In general, an increased understanding of the fundamental mechanisms governing these losses could help further improve production efficiencies. This review aims to summarize and evaluate the current scientific knowledge concerning metal losses and pinpoints the knowledge gaps.

First, the industrial importance and impact of metal losses in slags will be illustrated by several examples from both ferrous and non-ferrous industries. Throughout the remainder of this review, the main focus will be put on the particular issues in copper industry. In a second section, the different types of metal losses in slags will be discussed. Generally, metal losses in slags can be subdivided into two types: chemical losses and physical losses. The fundamental insights concerning the responsible mechanisms will be discussed for each type. Subsequently, an overview of the most frequently used techniques for research investigations of the losses will be given. In a fourth section, a more detailed overview will be given on the post-processing treatment of metal-containing slags, i.e. performing slag cleaning operations. The most frequently applied methods will be discussed.
\end{abstract}

\section{Keywords}

Pyrometallurgy; Metal losses; Slags; Chemical dissolution; Mechanical entrainment 


\section{Introduction}

The domain dealing with extraction or refinement of materials/metals at high temperatures is called pyrometallurgy. The raw materials for metal production (mined ores) contain less and less of the desired metal, thus increasing the ratio of produced slag to produced metal. The slag used to be considered as a waste stream, but is now considered as a secondary resource, e.g. in road building applications or dike fortifications. [1] Due to the recent higher demand on a lot of metals, the decrease in the quantity and purity of the corresponding ores and the increase in the amount of scrap, recycling becomes more important. Besides recycling, it is also necessary to improve and optimize existing processes in extractive and recycling metallurgy to deal with the scarcity of natural resources. [2]

In a pyrometallurgical process, several phases can be present besides the liquid metal: slag (mixture of metal oxides), matte (mixture of metal sulphides), etc. The slag mainly contains the gangue ores, from which the metal is extracted, and is mostly used to remove certain impurities. Moreover, it is also used as an isolation layer and prevents re-oxidation of the molten metal, because in a typical pyrometallurgical process, the slag floats on top of the molten metal, due to differences in density. In most pyrometallurgical processes, the slag will finally be tapped from the furnace. [1] Sedimentation is frequently one of the last steps (before tapping) in many pyrometallurgical processes, allowing separation of slag and matte/metal. However, industrial $\mathrm{Cu}$ smelters [3], $\mathrm{Pb}$ reduction smelting furnaces [4,5], ferrochrome smelters [6], etc. still suffer from metal rich droplet losses in slags due to insufficient phase separation. These losses remain an important issue in metal extraction and recycling industries and can be reduced by optimizing the phase separation. The focus in this study lays on $\mathrm{Cu}$ smelting, but it is clear that a fundamental investigation of the problem of metal losses in slags can yield solutions that are applicable in multiple industries.

This review is meant to summarize the scientific work performed regarding metal losses in slags. Therefore, first, the general aspects of the different possible metal production routes for the various base metals are discussed. Then, the different types of metal losses are discussed in detail, followed by possible experimental set-ups used to investigate these metal losses. Afterwards, several slag-cleaning operations are described to finally conclude with the summary. The emphasis lays on the scientific investigation of metal losses and some possible suggestions are made for minimization of metal losses throughout the text. The subsequent practical implementations, however, depend on the process under consideration and will not be discussed in this manuscript.

\section{Base metal production}

\subsection{Copper smelting}

Copper ores commonly consist of a low concentration (0.5-2 wt\% $\mathrm{Cu}$ ) of copper-iron-sulphide or coppersulphide minerals (e.g. chalcopyrite $\mathrm{CuFeS}_{2}$ or chalcocite $\mathrm{Cu}_{2} \mathrm{~S}$ ) in combination with a large amount of gangue material $\left(\mathrm{Al}_{2} \mathrm{O}_{3}, \mathrm{SiO}_{2}, \ldots\right)$. Pure copper metal is produced from these ores by concentration, smelting and refining. [7] The ores are concentrated by e.g. froth flotation, after which they are smelted in a large hot $\left( \pm 1250^{\circ} \mathrm{C}\right)$ furnace. Under oxidizing conditions, $\mathrm{Cu}$ tends to form metallic $\mathrm{Cu}$ as well as $\mathrm{Cu}$ oxide, as explained extensively by Yazawa [8]: the addition of oxygen to $\mathrm{Cu}_{2} \mathrm{~S}$ yields $\mathrm{Cu}$ instead of $\mathrm{Cu}_{2} \mathrm{O}$. When the latter happens, the $\mathrm{Cu}_{2} \mathrm{O}$ dissolves in the slag generated during copper making. The large concentration of iron in most copper concentrates creates a large amount of slag, which could allow for more $\mathrm{Cu}$ to be lost in it. As a result, it is better to eliminate some of the iron from the concentrate before final copper making. This is why the $\mathrm{Cu}$ ores are smelted first to produce a $\mathrm{Cu}$-rich matte $(45-75 \mathrm{wt} \% \mathrm{Cu})$ 
and a slag (with the smallest possible concentration of $\mathrm{Cu}$ ), after which this $\mathrm{Cu}$-matte is converted to form impure molten copper $(99 \mathrm{wt} \% \mathrm{Cu})$ in a separate step. To keep the concentration of $\mathrm{Cu}$ in the smelting slag as low as possible, it is possible to add a $\mathrm{SiO}_{2}$ flux to promote slag-matte immiscibility or to keep the furnace hot enough to liquefy the slag. [7]

The converting step takes place in two sequential stages: the elimination of Fe and other remaining impurities in the 'slagging blow' and the 'copper making blow', which converts the 'white metal' $\left(\mathrm{Cu}_{2} \mathrm{~S}\right)$ to metallic $\mathrm{Cu}$. The copper is then refined in further steps. Because conditions in the converter are strongly oxidizing, converter slag inevitably contains $4-8 \mathrm{wt} \% \mathrm{Cu}$. The slag can be treated to recover the remaining $\mathrm{Cu}$ and is then sold or discarded. Another possibility is the reuse of the converter slag as a starting bath for the next batch. [7] But this may also affect the final slag loss, because the oxygen potential of the melt is changed and this influences the composition of the matte and the slag. [9] The secondary production of copper uses scrap as a source of copper. High-purity copper scrap can be found in e.g. electronic wires and electronic waste. [7] It should be noted that the general aspects of primary copper production and scrap recycling are similar. A major difference in the case of scrap recycling is the use of copper as a collector metal for the noble metals, whereas in ore-based production, the primary aim is to produce the pure metal. The yields of the recycling of noble metals could be improved by higher collection rates of e.g. e-scrap and maximizing eco-efficiency.

\subsection{Lead smelting}

The conventional primary lead production process consists of four steps: sintering, smelting, drossing and refining. Feedstock mainly made up of lead concentrate is fed into a sintering machine together with other raw materials like silica, coke and limestone flux. This is fed in turn into a blast furnace for reduction with carbon, which also acts as fuel. Four layers form in the furnace: 'speiss' (the lightest materials, basically arsenic and antimony), matte (copper sulphide and other metal sulphides), blast furnace slag (primarily silicates) and lead bullion. Subsequently, all layers are drained off. The speiss and matte are sold for recovery of copper and precious metals to copper smelters. The blast furnace slag, which contains iron, zinc, silica and lime, is stored in piles and is partially recycled. The rough lead bullion from the blast furnace usually requires preliminary treatment, before undergoing refining operations. Then, the bullion is agitated in a drossing kettle and cooled just above its solidification point, $370^{\circ} \mathrm{C}-425^{\circ} \mathrm{C}$. A dross composed of lead oxide, along with copper, antimony and other elements floats on the top and solidifies above the molten lead. The dross is removed and is fed into a dross furnace for recovery of non-lead minerals. The lead bullion is further refined to remove any remaining non-lead materials in a cast-iron kettle in five stages, leading to lead with a purity of $99.9-99.99 \%$. Secondary production of lead uses old leadcontaining scrap as feed. The main scrap source are lead-acid batteries. [10]

\subsection{Nickel production}

Nickel can be extracted from sulphide ores, where pentlandite $\left((\mathrm{Ni}, \mathrm{Fe})_{9} \mathrm{~S}_{8}\right)$, chalcopyrite $\left(\mathrm{CuFeS}_{2}\right)$, and pyrrhotite $\left(\mathrm{Fe}_{7} \mathrm{~S}_{8}\right)$ are the major minerals. Mined sulphide ores contain typically about $1 \% \mathrm{Ni}$, and are concentrated to 7 to $20 \mathrm{wt} \% \mathrm{Ni}$ by various mineral processing methods. The concentrate is subsequently dried for further handling. Molten matte from the smelting furnace is transferred into a converter for the removal of the final FeS to form a matte with about 0.5 to $2 \mathrm{wt} \%$ Fe. This is achieved by blowing air or oxygen enriched air into the matte. It is during this stage with high oxygen pressures that the most valuable metal losses to the slag phase occur, as stated by Toscano and Utigard [11].

\subsection{Steel production}


During the production of crude / pig iron in a blast furnace, oxygen and other impurities are removed from the iron oxide ores by pyrometallurgical processes with carbon reducing reagents and fluxes. Most of the impurities and fluxing agents combine to form a liquid silicate melt called blast furnace slag. This slag is tapped from the blast furnace separately from the iron. The crude iron is then transferred to a steel furnace, either BOF (basic oxygen furnace) or EAF (electric arc furnace), where the iron's residual carbon content of about $4 \mathrm{wt} \%$ is reduced and other impurities are removed. This process involves the use of lime and silicate fluxes and the formation of steel slag. Steel furnaces, particularly electric arc furnaces (EAF), also may be fed with scrap iron and steel, but again the impurities are removed by fluxing agents which form a slag. Apart from the original furnace feedstock impurities, slags (especially steel slags) also may contain significant amounts of entrained free metals. [12]

\section{- Ferrochrome production}

In the production of stainless steel, ferrochrome is the major chromium source. The chromite ores are smelted using suitable carbonaceous reductants such as coke, char etc. During the smelting process, slag is formed and metallic ferrochrome coalesces into droplets, which separates from the slag by settling through the slag to the bottom of the furnace. Ferrochrome slag consists mainly of $\mathrm{SiO}_{2}, \mathrm{Al}_{2} \mathrm{O}_{3}$ and $\mathrm{MgO}$ in different proportions, but also smaller concentrations of $\mathrm{CaO}$, chromium and iron oxides, with significant quantities of chromium in the form of partially altered chromite and entrained alloy. [6]

\section{- Ferrovanadium production}

Ferrovanadium alloys are produced commercially by the reduction of vanadium ore, slag or technical grade vanadium oxide with ferrosilicon, aluminum and to a lesser extent by carbon. A charge consisting of vanadium oxide, reductant, fluxing agents, etc. is fed to an electric arc furnace that is maintained at temperatures of about $1600^{\circ} \mathrm{C}$, yielding either a 40 or $80 \% \mathrm{~V}$ alloy. The nature of the vanadium oxide used as input materials governs the choice of the production route. The use of $\mathrm{V}_{2} \mathrm{O}_{5}$ as raw material leads to the exothermic reduction, allowing that both iron and the alloy can melt, which results in an effective separation of the alloy and the high alumina slag. Therefore, an aluminothermic reactor can be used. When $\mathrm{V}_{2} \mathrm{O}_{3}$ and $\mathrm{V}_{2} \mathrm{O}_{4}$ are used as raw materials, addition of external energy is required to sustain the less exothermic reactions. Thus, the electro-aluminothermic reactor is used. The trivalent oxide is reduced with aluminium in an electric arc furnace, adding iron in the form of scrap, and lime ( $\mathrm{CaO})$ to flux the alumina. A high temperature for tapping $\left(1840{ }^{\circ} \mathrm{C}\right)$ is required because of the high melting point of ferrovanadium and also favours the settling of entrained metal droplets from the slag after tapping. $[13,14]$

\section{Metal losses in slags}

Large bubbles are produced during the gas-blowing stages in smelting and converting in several metal production processes. After each stage of gas blowing through the melt, a sedimentation step is necessary before phases can be tapped. The settling time of this step needs to be long enough to allow the different phases to separate, but this time also implies a loss of production time and, consequently, insufficient separations are often encountered in practice. E.g. some metal or matte droplets are often observed as a suspension in the slag. Several industries encounter such losses:

$$
\text { - Lead smelting }
$$

One of the factors impeding the total recovery of the lead contained in the sinter is the retention of metal by slag. It is generally accepted that when these losses exceed 2-3\%, the economics of the process are 
strongly affected. Excessive losses of lead frequently occur in the slag of lead blast furnaces which represents a sizeable economic loss for large scale production furnaces. $[4,5]$

- Nickel production

According to Solar [15], about two thirds of the total loss occurs in the electric furnace slag, as both dissolved nickel oxide and entrained metal droplets. These chemical and mechanical losses are reported equally. The amount of mechanical losses can vary between different nickel production plants. [15] Furthermore, cobalt, selenium and tellurium are valuable by-products in nickel sulphide smelting and are economically very important. The distribution of these minor elements, however, also affects the quality of the final product and the revenues gained from the by-product. For example, there are cobalt losses to the slag phase during the smelting and converting processes, leading to a conversion of only 30 to $60 \%$ of recovery for the matte phase. [16]

- Steel production

Gudim [17] studied the metal losses during steelmaking in arc furnaces. Metal enters the furnace slag in the form of a film on CO-bubbles, originating from carbon oxidation and in the form of droplets during oxygen blowing. The entrained metal content in the slag can be at least $10 \%$ of the metal mass during oxygen blowing of the bath. Gravity lets the metal droplets settle down from the slag in the metal phase. As the slag goes down in the furnace, its temperature decreases, its viscosity sharply increases, and the conditions for droplet settling deteriorate drastically. Therefore, metal droplets smaller than $3 \mathrm{~mm}$ are usually retained in the slag. The average content of iron in oxidizing steel melting slags is believed to be slightly lower than $20-25 \%$, including $10-15 \%$ metallic iron. [17]

\section{o Ferrochrome production}

Losses of metal to slag are observed with a significant amount of alloy droplets with a size of $30 \mu \mathrm{m}$ up to $2000 \mu \mathrm{m}$. Some entrained droplets $(>1 \mathrm{~mm})$ can be recovered back in the metallic phase, but the remainder stays entrained in the slag. Metal losses to slag can occur throughout the reduction process in the furnace, as well as during the tapping. Both mechanical and chemical losses occur. The slag is further treated to recover some of the entrained metal. The dissolved chrome can be controlled through improved redox-basicity control, while the amount of entrained chrome can be controlled through the control of the slag viscosity. [6]

\section{o Ferrovanadium production}

As stated by Vermaak [13], the vanadium recovery in the electro-aluminothermic process is mainly controlled by vanadium losses in the slag, which include metal droplet entrainments and unreduced vanadium oxides in the slag.

\section{- Copper smelting}

Last century, the subject of copper losses in slags was already reviewed by Aksoy [18] and Yannopoulos [3]. Yannopoulos [3] depicted the monetary significance of the copper losses by comparing the losses with other important smelting operational costs, as represented in Fig. 1.

The amount of losses depends on the industrial processes used, i.e. which type of furnace. The newer processes produce higher grades of matte, which results in slags with higher copper content. Sridhar et al. [19] estimated that for the annual worldwide primary copper production of $9 \mathrm{Mt}, 181 \mathrm{kt}$ of copper are discarded via the slag, which represented 400 million dollar at that time. Note that nowadays the yearly copper production is about $19 \mathrm{Mt}$ [20]. 
Smelting furnace slag contains roughly $1-2 \% \mathrm{Cu}$, which rises as the matte grade increases according to Davenport et al. [7] Converter slag contains roughly 4-8 \% Cu [7] and smelting slags from the Teniente converter contain up to $8 \mathrm{wt} \%$, according to Warczok et al. [21]. Based on compositions of several industrial slags, Shen [22] noted that the copper content varied between 0.5 and $3.7 \mathrm{wt} \%$. Taking into account the mass of each produced slag, a significant amount of copper is present in this slag. $[7,23]$ Tan [24] described the amount of losses of the Xstrata Copper Smelter process at Mount Isa and concluded that the copper lost to rotary holding furnaces is the single largest loss in the copper smelter. As stated by Degel et al. [25], metal losses in the copper industry are one of the main factors determining the overall plant recovery.

In order to make the pyrometallurgical processes more efficient and minimize metal losses, more knowledge is required on the form and origin of these losses. A small amount of literature can be found on the influencing factors for the decantation of metals in slags. Nevertheless, it is generally accepted $[3,9,19,26,27]$ that the metallic losses in slags have two causes: the chemical dissolution of metals and the mechanical entrainment of metallic droplets. The chemical dissolution of metals is inherent in pyrometallurgical processes and governed by the system's thermodynamic equilibrium. The amount of dissolved metal is correlated with the thermodynamic state of the furnace. $[9,27]$ The difference between the actual amount of copper present and the amount that can be attributed to its dissolution, is usually assigned to the formation of a mechanical dispersion of matte/copper in the slag. [28] Fig. 2 shows the copper losses in slags as a function of the matte grade in the Tamano flash smelter as indicated by the shaded frame. Maruyama et al. [29] simulated the chemical copper losses within this industrial set-up, using HSC chemistry. The difference between the simulations and the actual industrial data were assumed to be attributed to mechanical losses (indicated by suspension loss).

Apart from the economic losses associated with these droplets, the process becomes more difficult to handle when $\mathrm{Cu}$ droplets are present. The process aspires to an optimal quantity of Cu-oxide in the slag: the amount of copper in the slag is determined by analyses and this sets the oxygen quantity. There is, however, no way to notice the difference between metallic $\mathrm{Cu}$ (in the droplets) and the oxidized form (dissolved in the slag) in the short time span available during processing, because the analyses to discover the difference take too long. This indicates that the process control is not optimal. The copper smelting process at this moment is controlled based on experience, but a better separation can probably be obtained when a more fundamental knowledge of the interactions and phenomena in the formation of droplets and decantation is constructed. The different types of losses will be discussed in more detail in the following sections.

\subsection{Dissolved metal}

Chemical dissolution of metals in slags has already been investigated thoroughly in literature [8,30-32]. Initially, copper (and other metals) were assumed to be dissolved in slags as oxides, called the 'oxidic' dissolution. The $\mathrm{Cu}_{2} \mathrm{O}$ concentration in a slag is related with the thermodynamic state of the furnace and it can be minimized by controlling the furnace according to well-studied metal-matte-slag-gas relationships. [27] The oxidic copper solubility increases with increasing $p_{02}$ and decreasing temperature. $[9,32]$ The effect of the temperature can be observed in Fig. 3 and the influence of $p_{02}$ in Fig. 4.

Increasing the matte grade also results in a higher copper content in the slag. [3] The silica content can also influence the $\mathrm{Cu}$ losses. It was found that the minimum loss of copper due to mechanical entrainment is found at approximately $35 \% \mathrm{SiO}_{2}$. This decrease up to $35 \%$ is accounted for by the predominance of the interfacial tension of slag and matte over the viscosity of the melt. $\mathrm{SiO}_{2}$ addition increases the viscosity 
and decreases the surface tension. The silica content also has an influence on the magnetite formation (the ratio $\mathrm{SiO}_{2} / \mathrm{FeO}$ is important). [3] Other slag constituents also influence the amount of copper lost: increasing $\mathrm{FeO}$ decreases the viscosity, increases the density and enhances the reduction of magnetite which in turn enhances the solubility of copper in slag (by forming $\mathrm{SO}_{2}$ bubbles). The solubility of the matte in the slag is reduced with increasing $\mathrm{CaO}$ content, because it reduces the specific gravity and lowers the melting point and the viscosity. $\mathrm{CaO}$ also increases the surface and interfacial tension. $\mathrm{Al}_{2} \mathrm{O}_{3}$ increases the viscosity of the slag, it should, however, be noted that the effect on the copper losses depends on which other slag constituent the alumina replaces. $\mathrm{MgO}$ acts in the same way as $\mathrm{CaO}$ if it is added in small amounts. [3] $\mathrm{CaO}$ is the most effective in decreasing the copper solubility, followed by $\mathrm{MgO}$ and $\mathrm{Al}_{2} \mathrm{O}_{3}$, this order corresponds to that of the basicity of these additives. The results can be explained by the acidbase theory of the slags: the ions of the additives $\left(\mathrm{Ca}^{2+}, \mathrm{Mg}^{2+}\right.$ and $\left.\mathrm{Al}^{3+}\right)$ replace some of the copper ions and occupy sites in the silica structure. [33] Addition of more basic oxides $\left(\mathrm{CaO}, \mathrm{Na}_{2} \mathrm{O}\right)$ produces an excess of $\mathrm{O}^{2-}$ anions and thus results in a basic slag. Acidic oxides $\left(\mathrm{P}_{2} \mathrm{O}_{5}, \mathrm{Al}_{2} \mathrm{O}_{3}, \mathrm{Fe}_{2} \mathrm{O}_{3}\right)$, on the contrary, behave similar as silica and produce very stable tetrahedral anions with a negative charge of -3 , i.e. a combination of the cation and 3 or 4 oxygen anions, which are capable of polymerisation to larger ionic compounds. The ability of an oxide to be acidic or basic can be measured by the attraction of the cation to an oxygen ion. If this attraction is larger, the oxide will less likely dissociate into $\mathrm{O}^{2-}$ anions and thus a greater acidic tendency of the oxide exists. A measure for this is the ionic bond fraction (Table 1), i.e. the fraction of the whole bond that can be considered ionic, as opposed to a covalent bond. For a binary compound, a higher ionic bond fraction yields a more basic oxide. Another measure for the attractive force between the metal ion and oxygen is the ratio $\mathrm{Z} / \mathrm{a}^{2}$ with $\mathrm{Z}$ the charge of the metal ion and a the sum of the radii of the two ions. [34]

\begin{tabular}{|c|c|c|c|c|c|c|c|c|c|c|c|c|c|c|}
\hline Oxide & $\mathrm{Na}_{2} \mathrm{O}$ & BaO & SrO & $\mathrm{CaO}$ & MgO & MnO & Zno & $\mathrm{Al}_{2} \mathrm{O}_{3}$ & $\mathrm{Cr}_{2} \mathrm{O}_{3}$ & $\mathrm{TiO}_{2}$ & $\mathrm{FeO}$ & $\mathrm{Fe}_{2} \mathrm{O}_{3}$ & $\mathrm{SiO}_{2}$ & $\mathrm{P}_{2} \mathrm{O}_{5}$ \\
\hline $\begin{array}{c}\text { lonic } \\
\text { bond } \\
\text { fraction }\end{array}$ & 0.65 & 0.65 & 0.61 & 0.61 & 0.54 & 0.47 & 0.44 & 0.44 & 0.41 & 0.41 & 0.38 & 0.36 & 0.36 & 0.28 \\
\hline $\mathrm{z} / \mathrm{a}^{2}$ & 0.18 & 0.27 & 0.32 & 0.35 & 0.48 & 0.42 & 0.44 & 0.83 & 0.72 & 0.93 & 0.44 & 0.75 & 1.22 & 1.66 \\
\hline $\begin{array}{c}\text { Oxide } \\
\text { type }\end{array}$ & \multicolumn{4}{|c|}{ Basic } & \multicolumn{8}{|c|}{ Intermediate } & \multicolumn{2}{|c|}{ Acidic } \\
\hline
\end{tabular}

Table 1 Comparison of character of oxides and measures for this character: ionic bond fraction and ratio of charge of metal ion over the square of the sum of the two ionic radii [34]

Richardson and Billington [35] concluded for sulphur-free slags that copper can only be dissolved after being oxidized and no solubility of atomic copper is present. When the slag coexists with a sulphidic matte phase, the iron silicate slag can dissolve additional copper. Thanks to the ionic theory, the concept of 'oxidic' and 'sulphidic' dissolutions of copper was developed to explain this phenomenon. [9] Sehnalek and Imris [36] and Nagamori [37] were the first to recognize the sulphidic dissolution of copper. Nagamori found the copper solubility in his experiments to be far greater than that attributed to oxidic loss according to previous work (which was performed on sulphur-free slags). The solubility was related to the presence of sulphur in the slag and the concept of sulphidic dissolution was developed. The molecular or ionic theory of a slag states that a sulphur ion may dissolve in the slag as if it replaces a free oxygen ion, which was originally associated with an iron ion. The sulphur ion may in turn tend to replace some of its coordinating iron ions with copper in accordance with the activity of copper in the matte.

The total dissolved copper in the slag is the sum of the oxidic and sulphidic dissolution. The fractions of both kinds of dissolved copper depend on the composition of the slag. The sulphidic dissolution is in general important for matte grades up to approximately $60 \% \mathrm{Cu}$, while oxidic dissolution is the significant 
mechanism otherwise [9], as illustrated by Fig. 5 [38]. To decrease the dissolved copper loss in slag, it is effective to raise the $\mathrm{Fe} / \mathrm{SiO}_{2}$ ratio to decrease the oxidic loss. In order to decrease the sulphidic loss, this ratio should be lowered. [29]

An increase in $\mathrm{Al}_{2} \mathrm{O}_{3}, \mathrm{MgO}, \mathrm{CaO}$ or $\mathrm{SiO}_{2}$ decreases the mutual dissolution between matte and slag, thus the dissolved sulphide content in the slag and the dissolved oxide content in the matte decreases. [8] Apart from the decrease in copper solubility, the $\mathrm{Fe}^{3+} / \mathrm{Fe}^{2+}$ ratio was also lowered due to the additions of $\mathrm{CaO}, \mathrm{MgO}$ and $\mathrm{Al}_{2} \mathrm{O}_{3}$. This effect, however, was smaller at lower oxygen potentials. [33]

Even though it was universally agreed that dissolved copper in slag occurs as both copper sulphide and copper oxide, [26] this idea has been rejected by Gaskell et al. [39] and Sridhar et al. [19]. It was observed that the original data of Nagamori [37] show that the copper content in slags decreases as the sulphur content increases and Sridhar et al. [19] also pointed out that normal investigations use a gas-matte equilibrium to control the oxygen potential (similar as in plant practice). Nagamori used metallic iron in equilibrium with 0-55wt\% Cu mattes to control the oxygen potential. With this method, the oxygen potential is lower than in copper smelting and this increases the sulphur solubility. For Cu grades of mattes above $55 \mathrm{wt} \%$, Nagamori used copper metal in contact with matte to fix the oxygen potential. This results in an oxygen potential close enough to that in copper smelting. It was observed by Nagamori that in this latter composition range the copper loss is only oxidic. The observations of Sridhar et al. [19] imply that the copper losses in slags can be explained by the oxidation of copper at different oxygen potentials present during the production of different matte grades. No assumption of copper sulphide species in the slag is needed to explain copper losses. Moreover, according to Sridhar et al. [19], it is very unlikely that copper sulphide is present, as the affinity of sulphur for Fe is higher than for $\mathrm{Cu}$. This leads to a higher probability for sulphide ions to be present in the proximity of iron ions. Victorvitch [40] drew a similar conclusion in extensive studies on copper smelting slags.

\subsection{Mechanically entrained metal droplets}

The difference between the actual and thermodynamically predicted metal content in slags can be attributed to the mechanical dispersion of metal and matte in the slag. A significant amount of literature deals with chemically dissolved metal losses to slags, but a large spread on the data is observed. This can be explained by the amount of physically entrained matte or metal, which is usually not measured and which is difficult to calculate accurately. Mechanical losses in the slag can make up to $65-80 \%$ of the total copper loss. Mechanical losses depend on the way the furnace is operated, slag viscosity, fluid motion in the slag, residence time, $\mathrm{SO}_{2}$ generation in the melt, the presence of solid particles which can trap matte droplets and the matte-slag separation. [9]

The losses due to the droplets are far less controllable than the dissolved metal losses. They are associated with the inadequate decantation of the droplets. The mechanical losses are particles with varying sizes from several $\mathrm{mm}$ to a few $\mu \mathrm{m}$. $[26,41] \mathrm{In}$ general, settling of droplets of a certain phase in another phase can be described by Stokes' equation:

$$
u=\frac{2 r^{2}\left(\rho_{\text {sphere }}-\rho_{\text {fluid }}\right) g}{9 \mu}
$$

Where $\mathrm{u}$ is the settling rate $(\mathrm{m} / \mathrm{s}), \rho_{\text {sphere }}$ and $\rho_{\text {fluid }}$ the density of the droplets and the surrounding phase respectively $\left(\mathrm{kg} / \mathrm{m}^{3}\right), r$ the radius of the droplet $(\mathrm{m}), g$ the gravity constant $\left(\mathrm{m} / \mathrm{s}^{2}\right)$ and $\mu$ the viscosity of the slag (Pa.s). This equation is valid for laminar flow conditions, which are characterized by a low Reynold number, for rigid spheres or drops/bubbles and approximately valid for liquid droplets rising or settling in 
an immiscible medium characterized by an immobile surface. [42] Larger copper droplets in slags in industrial processes, however, are not necessarily rigid and do not maintain their spherical shape. If the viscosity of the copper droplets is much lower than the viscosity of the slag, internal tensions are created within the droplets and Stokes' equation should be corrected to the Hadamard-Rybczinski equation: $[43,44]$

$$
u=\frac{g \cdot r^{2} \cdot \Delta \rho}{3 \mu}
$$

where $\Delta \rho$ represents the density difference between the sphere and the fluid. It was found in early experiments that small drops with a diameter less than $0.01 \mathrm{~cm}$ behave like rigid spheres as their velocity is described by the Stokes' equation [45]. On the other hand, drops of a sufficiently large size fall within velocities described by the Hadamard-Rybczinski equation. [46] The Stokes and the Hadamard-Rybczynski equation emphasize the importance of the slag viscosity, the size of the sinking droplets and the density difference. To get a fast decantation, the following should be aimed for: [3]

- the difference in density as high as possible. The density of iron silicate slags in copper smelting decreases with the increase in silica content, a decrease in temperature and also with an increase in basic oxide levels. Generally, $\mathrm{FeO}$ increases the slag density, while $\mathrm{SiO}_{2}$ and $\mathrm{CaO}$ have the opposite effect.

- the size of the droplets as large as possible. Larger droplets can be achieved by coagulation or growth of smaller droplets. This increases the surface/volume ratio, which is related to the interfacial energy between the droplets and the slag. The droplets can also grow or shrink due to reduction or oxidation reactions.

- the viscosity of the slag should be as low as possible. In the case of high viscosity liquids, small particles can remain entrapped for long periods of time. [47] It should be noted that the viscosity of the slag depends on the fraction solid particles, this is called the "slurry effect" (which is described by the Einstein-Roscoe model equation:

$$
\eta=\eta^{0}(1-a f)^{-n}
$$

with $\eta$ the viscosity of the liquid melt with solid particles dispersed in it (Pa.s), $\eta_{0}$ the viscosity of the liquid without solid particles (Pa.s), $f$ the fraction of solid particles in the melt, $a$ the inverse maximum fraction of solid particles and $n$ a constant related to the geometrical particles shape, which is assumed to be 2.5 for spherical particles [48]). The settling rate can be increased by decreasing the viscosity or by using a more reducing environment, as the $\mathrm{Fe}_{3} \mathrm{O}_{4}$ content of the slag will be decreased. [7]

The settling rate has an important influence on the efficiency of the sedimentation process. Maruyama et al. [29] investigated the influence of the settling time on suspension losses. As expected, it was confirmed that the copper content in the slag layer decreases with increasing settling time. The settling of suspended particles using the Stokes' equation was calculated and is presented in Fig. 6. [29] For the Tamano Flash smelting furnace, the average settling time of the slag is 4 to 5 hours. Within this time frame, particles with a size larger than 0.13 to $0.15 \mathrm{~mm}$ diameter settled. Longer decantation times only have a limited effect on the recovery of the smaller particles. [29]

It was generally believed that phase separations in slag-metal systems occur only due to the buoyancy effect (the large difference in density of the alloy and the slag). Lau et al. [49] checked this hypothesis, by investigating the influence of different gravity conditions on the products synthesized by combustion phenomena. Different systems were investigated in a variety of gravity conditions from $10^{-5} \mathrm{G}$ up to $1.7 \mathrm{G}$ (this corresponds to overload gravity and is achieved in a part of the trajectory during parabolic KC-135 
flights). The investigation showed that mechanisms driven by surface energy might also play an important role in the settling process. [49] Also note that some copper matte or metal droplets can retain on the surface of the slag due to surface forces, which was experimentally observed by Fagerlund [50]. Poggi et al. [47] defined the critical radius of a droplet that can rest on the interface by equating the upward force due to surface tension and the weight of the particle (or drop):

$$
R=\left(\frac{2 \cdot \gamma_{\text {slag }}}{4 / 3 \cdot \rho_{\text {particle }} \cdot g}\right)^{1 / 2}
$$

With $R$ the critical radius of sphere $(\mathrm{m}), \rho$ the density $\left(\mathrm{kg} / \mathrm{m}^{3}\right), g$ the gravity constant $\left(\mathrm{m} / \mathrm{s}^{2}\right), \gamma$ the surface tension $(\mathrm{N} / \mathrm{m})$. It is expected that larger drops sink through the slag/metal or matte surface and that smaller drops float.

Up to this point, the phenomenon of mechanically entrained droplets was described. However, the question remains where and how do these droplets originate? Mechanically entrained matte or metal droplets in slag can originate from a variety of sources: [51,52]

1. Entrainment due to charging of the furnace or tapping of the slag

2. Precipitation of copper from slag due to temperature or oxygen level gradients within the furnace or due to chemical reactions

3. Sulphur dioxide gas, produced in the matte phase, or other gas phases dispersing the matte into the slag as the gas crosses the matte-slag interface

4. Attachment of matte/metal droplets to solid particles present in the slag phase which hinder their settling

The different possibilities will be discussed in more detail in the following sections.

\subsubsection{Entrainment due to charging of the furnace or tapping of the slag}

Liow et al. [53] studied slag tapping operations in the settler region of a copper flash furnace and their influence on the entrainment of a two-layer liquid through a tap hole. Paraffin oil was used in the experiments to resemble the slag, which is more viscous than the heavier metal or matte phase. Water and salt solutions were used to simulate the matte or metal layers. It was observed that a simple ledge can effectively reduce entrainment, due to the formation of a meniscus by the lower liquid layer on that ledge which inhibits the flow.

\subsubsection{Precipitation of copper from slag due to temperature or oxygen level gradients within the furnace or due to chemical reactions}

Regarding the second possibility, it should be noted that the slag phase in industry might not be homogeneous, and local variations in temperature or oxygen levels are possible. The dissolution of copper in the slag is influenced by those parameters, cf. section 3.1. Thus, certain zones in the slag might be characterized by a lower copper solubility, leading to the precipitation of oxidized copper present in the slag as metallic copper droplets. Moreover, a large part of the copper dissolved in the slag can precipitate as metallic copper from iron-silicate slags, even in quenching, according to Jalkanen et al. [28]. In quenched slags, copper is said to be evenly distributed as small size precipitates. The copper particles in a quenched slag are regularly surrounded by a dark sphere. The precipitation of copper during the quenching of the slag is said to be caused by the disproportion reaction of cuprous oxide with $\mathrm{Fe}^{2+}$-ions in equation 5. This reaction yields metallic copper and $\mathrm{Fe}^{3+}$ and explains the rapid disproportion, as 
supported by the observations of Vehviläinen and Imris et al. $[26,28]$ who suggest that copper is often surrounded by magnetite. [28]

$$
\mathrm{Cu}_{2} \mathrm{O}+3 \mathrm{FeO} \leftrightarrow 2 \mathrm{Cu}+\mathrm{Fe}_{3} \mathrm{O}_{4}
$$

Whenever mass transfer takes place at a certain liquid-liquid interface, various transitory phenomena occur [54]:

- hydrodynamic phenomena originating from interfacial tension gradients,

- lowering of dynamic interfacial tension when mass transfer at the interface is intense,

- spontaneous emulsification by 'diffusion and stranding' mechanisms.

These effects are evidenced by the deformation of a metal drop, immersed in a slag, during intense mass transfer between the two phases. Gaye et al. [54] investigated the influence of mass transfer upon interfacial phenomena with X-ray observations at high temperature. It was shown that, when very high reaction rates are obtained, the tendency towards spontaneous emulsification exists and it was pointed out that part of the reaction takes place in the slag, at some distance from the interface, through a 'diffusion and stranding' mechanism. They also found that for various systems, the interfacial forces seem to disappear when the oxygen flux is larger than $0.1 \mathrm{~g} . a t o m /\left(\mathrm{m}^{2} . \mathrm{s}\right)$. Dispersion of one phase into the other may become extremely easy in this case and can occur without external mechanical energy.

Afterwards, Rhamdhani et al. [55] investigated reactions between liquid iron alloy droplets and a liquid slag at high temperature. The observed phenomena include droplet flattening or spreading (a decrease in apparent interfacial tension of the droplet), interfacial turbulence and spontaneous emulsification (the droplet breaks up into numerous smaller droplets). The first and the last of these possibilities can be observed in Fig. 7. This figure represents the sequence of steps encountered by Rhamdhani et al. [55,56] during their experiments: in the early stage of the reaction, the droplet has a nearly flat shape, but when the reaction is the most intense in the intermediate stage, numerous droplets, $\mathrm{mm}$ and $\mu \mathrm{m}$ in size, were obtained. Apart from this macroscopic emulsification, some microscopic emulsification was also observed in the stage prior to emulsification, some microdroplets can be found near the interface of the single droplet. But although many microdroplets can be observed, they do not change the interfacial area significantly.

It should be noted that both metal and slag emulsification are observed. Rhamdhani et al. [55] also observed the initiation of emulsification: an interfacial instability causes a protrusion of slag into the metal phase, as the tip goes further into the metal phase it will tend to become spherical to decrease its interfacial area; once necking occurs, detachment of the droplet is favourable in order to decrease its interfacial area; an emulsified slag droplet in the metal phase is then formed. The same mechanism may apply for metal protrusion into the slag leading to metal emulsification in the slag. The first emulsified droplets are in the $\mu \mathrm{m}$ size range, further they may coalesce to form bigger droplets (in the order of a few tens of $\mu \mathrm{m}$ ). A perturbed interface is only observed in the first stages of the reaction.

\subsubsection{Gas phases dispersing the matte into the slag as the gas crosses the matte-slag interface}

The third possibility ( $\mathrm{SO}_{2}$ gas bubbles crossing the interface) has been investigated thoroughly. [47] Any type of gas bubbles can have the same effect of taking matte or metal with it into the slag phase when the interface between the different phases is crossed. [57] Rising $\mathrm{SO}_{2}$-bubbles can find their origin in the reaction between iron sulphides and magnetite. This reaction is thought to take place near the furnace bottom and the charge banks. [47] Cuprous oxides dissolved in the slag can also react with either $\mathrm{Cu}_{2} \mathrm{~S}$ (in the matte) or a combination of solid $\mathrm{SiO}_{2}$ and $\mathrm{FeS}$ (in the matte) to produce $\mathrm{SO}_{2}$ gas bubbles. [58] 
This was also illustrated by Holappa et al. [57] for steel production. When gas bubbles pass through the iron/slag interface, small iron droplets burst into the surrounding slag (Fig. 8 (a)). When the gas bubble exits the interface to the slag phase, a jet is formed to fill the cavity with metal. This jet collapses and produces metal droplets into the slag phase, as illustrated in Fig. 9 (c and d) and Fig. 8 (b). It is interesting to note that they observed that with larger bubble size the mass of the entrained metal in the slag increases strongly and that smaller bubbles cause practically no entrainment of metal into slag. They also noted that an increase in the interfacial tension of the metal or in the viscosity of the slag reduced the metal entrainment.

Thus, the ability of gas bubbles to pick up droplets from the underlying phase into the upper phase is governed by the surface and interfacial tension of the involved liquid phases and gas. Three situations are possible, as shown in Fig. 10, where $L_{2}$ represents the underlying liquid phase and $L_{1}$ the upper phase. $[51,52,59]$

It was suggested that possibility (a) (formation of a film coating on the gas bubble) will occur if the spreading coefficient is positive. The spreading coefficient $\phi$ is defined as:

$$
\phi=\gamma_{L_{1} / g}-\gamma_{L_{2} / g}-\gamma_{L_{1} / L_{2}}
$$

Where $\gamma_{L 1 / g}$ is the surface energy of the upper liquid phase, $\gamma_{L 2 / g}$ the surface energy of the lower liquid phase and $\gamma_{L 1 / L 2}$ the interfacial energy between both liquids. The metal or matte coating of the bubble can subsequently rupture and scatter smaller droplets into the slag phase. The small droplets are scattered by the rupture of the film, they tend to sink to the lower liquid surface under gravity, but they may become entrapped as rafts of droplets, which float on the top surface of the slag due to surface tension forces or they can be suspended as droplets below small supporting gas bubbles or they may become entrapped in the slag due to the fact that they are extremely fine, hereby settling extremely slowly. [47]

Situation (c) (flotation of the droplet by a gas bubble with contact) will occur if the flotation coefficient (defined in equation 7) is greater than zero.

$$
\Delta=\gamma_{L_{1} / g}-\gamma_{L_{2} / g}+\gamma_{L_{1} / L_{2}}
$$

Situation (b) (flotation of droplets without contact with the gas bubble) will take place only if this flotation coefficient is less than zero.

The flotation behaviour can alternatively be investigated by the development of a ternary interfacial energy diagram based on the balance between surface and interfacial tension forces acting on a droplet resting on a liquid-liquid interface. [51] The conclusions of this and the abovementioned method are identical. [52] Ip and Toguri [51] made such a ternary interfacial energy diagram for the matte-slag-gas, copper-slag-gas, copper-matte-gas and copper-slag-matte systems at $1473 \mathrm{~K}$. They used it to show that matte droplets with more than $32 \mathrm{wt} \% \mathrm{Cu}$ will not form a film on rising gas bubbles when they collide in the slag phase. The matte droplets will attach themselves to the gas bubbles upon collision and can rise together with the gas bubbles, i.e. are floated, over the whole range of matte composition. Thus, matte flotation in the slag phase cannot be eliminated by altering the matte grade. [51]

Spreading of metallic copper on bubbles is not possible at oxygen pressures between $10^{-12}$ and $10^{-8} \mathrm{~atm}$. Flotation of copper by gas bubbles is possible at oxygen pressures higher than $10^{-9} \mathrm{~atm}$. Therefore, to avoid the entrainment of metallic copper, the oxygen pressure inside the furnace should be kept below $10^{-9} \mathrm{~atm}$. It should be noted that the possibility exists that copper droplets attach themselves to matte droplets and are floated by rising gas bubbles, irrespective to the matte grade. [51]

\subsubsection{Attachment of matte/metal droplets to solid particles present in the slag phase which hinder their settling}


The rather small amount of literature available on the fourth possibility (attachment to solid particles) mainly focusses on the observation of the phenomenon. Only recently, De Wilde et al. [60-62] investigated the phenomenon in more detail. The phenomenon is observed in industry as the attachment of $\mathrm{Cu}$ rich droplets to spinel particles present in the slag. The processes in the $\mathrm{Cu}$ smelter take place on temperatures ranging from 1180 to $1250^{\circ} \mathrm{C}$. Processing temperatures beneath $1200^{\circ} \mathrm{C}$ typically produce a subliquidus slag. Due to this subliquidus temperature, the slag contains solid particles, which influence the viscosity of the slag and can even cause entrainment of matte or metal droplets. [7]

Observation of $\mathrm{Cu}$ entrainment by solid particles has shown that these solid particles often possess a spinel structure. Investigation of the lead losses in the slag of a reduction smelting furnace by Calvo et al. [4] showed a relation between the amount of metal losses and the magnetite content. Microscopic investigation showed that the magnetite appeared to be associated with the lead particles, as illustrated in Fig. 11. The amount of magnetite present in the slag is determined by the reduction potential of the furnace, which can be indicated by the sulphur content of the slag (an adequate reduction potential increases the sulphur content).

An investigation of the slag of a ferrochrome smelter [6] shows the presence of $(\mathrm{Fe}, \mathrm{Mg})(\mathrm{Cr}, \mathrm{Al})_{2} \mathrm{O}_{4}$ spinel and these microstructural elements can be linked to the entrainment of metallic droplets, as shown in the pictures of Appendix B of reference [6]. Two of them are shown in Fig. 12.

The dependency of the amount of entrained $\mathrm{Cu}$ drops on the amount of spinel particles (and on the temperature) can be observed in Fig. 13.

Magnetite has different effects on the viscosity and settling of Cu droplets: [3]

- Magnetite can be reduced by FeS which produces $\mathrm{SO}_{2}$ bubbles, which in turn promote the flotation of matte or copper droplets into the slag, as described above.

- The presence of magnetite promotes the formation of copper ferrites.

- The presence of magnetite increases the viscosity of the slag, which reduces the settling of droplets, cf. Stokes' equation.

- The disturbance of the phase separation between the slag and matte or alloy through the formation of a magnetite false bottom between the slag and the matte or alloy layers (called a "mushy" zone).

Barker et al. [63] investigated the correlation between magnetite and copper amounts in slags and found a direct connection between the two. Afterwards other investigations delivered the same conclusion: Imris et al. [26] observed the correlation between magnetite content and copper losses in slags, as can be seen in Fig. 14 (a) and by Barker et al. [63] in an industrial experiment as shown in Fig. 14 (b).

Due to the combination of all interacting influences of magnetite, it is difficult to define a quantitative relationship between magnetite and copper content in the slag. $[3,58,63,64]$ Moreover, it should be noted that most industrial papers consider the magnetite content as a sign of the oxidation state of the slag and report the ferric oxide content of the slag, due to the fast precipitation of spinel solids during cooling. For other (spinel) solids present in slags, similar conclusions can be drawn: an increase in solids in slags will increase the viscosity of slags and lead to slower settling of entrained droplets, which subsequently leads to higher mechanical losses. Furthermore, the phase separation can be disturbed due to the presence of solids in different zones in the smelter. $[3,26,65]$ In addition, it is believed that the phenomenon of copper droplets attached to spinel particles is an important reason for spinel solids hindering the settling process. The presence of spinel solids can be explained by the operation temperature that must be subliquidus.

Nevertheless, it is not clear when or where the attached droplets originate. Are the Cu droplets formed together with the magnetite, according to the disproportion reaction or do the $\mathrm{Cu}$ droplets attach 
themselves to the already present spinel particles or a combination of both? No specific attention had been given to this phenomenon and no knowledge was available concerning the fundamental mechanisms responsible for it, until recently published work of De Wilde et al $[61,62,66,67]$. They were able to reproduce the attachment in a synthetic slag [61], as illustrated in Fig. 15.

After which they also investigated how this attachment influences the settling time [62] with a model based on the Hadamard-Rybczynski formula and experiments. In the experiments (Fig. 16), a clear decrease of the amount of mechanical entrained droplets was noticed in the upper slag layer as a function of time, together with a variation of the amount of mechanically entrained droplets as a function of slag height. Similar observations could be made for the spinel solids present in the slag. The settling rates calculated with the model were of the order of $1 \mathrm{~mm} / \mathrm{min}$, which corresponded with the experimentally obtained values. It was observed that the attachment hindered the complete settling towards the underlying copper phase, because the average density of the 'Cu-droplet - spinel' entity is lower than that of the underlying copper. Additionally, the presence of attached spinel particles can obstruct the coagulation of smaller droplets, which also lowers the settling rate.

The origin of the attachment was also investigated by sampling at different moments during smelting experiments. Moreover, a more fundamental approach was used to investigate the interaction: sessiledrop experiments of slag and/or metal on a spinel substrate at high temperatures $[66,67]$ showed that slag exhibits a better wetting than copper on spinel. This is in contrast with the observation that attached droplets remain attached and settle down. Thus, as slag exhibits a better wetting than copper on spinel, an energy barrier should be overcome by the copper droplets to expel the slag layer.

From these observations, De Wilde et al. [62] proposed two different ways to explain the origin of the attachment. Firstly, extensive stirring can be sufficient to induce the attachment. Secondly, a chemical reaction taking place during the evolution towards a thermodynamically more stable state can be responsible for the attachment. While the first assumption seems to be less likely as sticking droplets are also observed in experiments without any stirring, the second option was explored in more detail: a slag that is initially free of any Cu droplets was prepared. After the insertion of a steel bar in the system, the formation of sticking droplets was observed. [68]

A reaction scheme was proposed, including two possible pathways where the spinel solids form together with the copper droplets or form around the copper droplets, depending on the local conditions of the system. In both pathways, redox reactions involving copper (oxides) are essential and within the applied synthetic system, Fe and Fe-oxides play a crucial role. Within the slag system, two different types of spinel phases were present: an Al-rich spinel and an Fe-rich spinel. Throughout all experiments, it was observed that copper droplets were only attached to Fe-rich spinel solids. Furthermore, it was also observed some copper droplets were completely surrounded by spinel solids present in the slag system. Both observations, together with the fact that the attachment occurs even though the slag exhibits a better wetting than copper on spinel, support the explanation of the reactive origin of the attachment $[62,67,68]$.

These observations together with the observations of Durinck et al. [69] suggest a final experiment to confirm the reactive origin of the attachment. The addition of a more noble metal to the copper phase would give the opportunity to reveal whether the droplets present in the slag originate from a redox reaction of the slag (typically not containing the oxide corresponding to the more noble metal) or from the mixing of the slag and metal phase (which results in typically larger droplets containing the more noble metal). Durinck et al. [69] also found that a small concentration of iron oxide in the slag has an important effect on its 'reactivity', which might be linked to the fact that iron is a multivalent cation. 


\section{Experimental methodologies}

Metal losses in slags can be studied with a variety of methodologies. A first common approach is the use of water-based systems at room temperature. The dispersion of one liquid into another was studied by the use of several liquid combinations, resembling different density ratios (( $\left.\left.\rho_{\text {heavier }}-\rho_{\text {lighter }}\right) / \rho_{\text {lighter }}\right)$ : oil/water [70,71], oil/mercury [47], kerosene/water [53,72], mercury/ water-glycerine [47] and paraffinwax/water [53] systems were already investigated in literature. This type of experiments is very useful to gain information regarding temperature independent processes. Poggi et al. [47] made qualitative high speed photographic observations of transport and entrapment mechanisms of argon bubbles carrying a mercury film into the water-glycerine mixture. Liow et al. [53] used this type of experiment to determine the conditions for the entrainment of a second liquid during the withdrawal of the first liquid. The drawback of this type of procedures is that only mechanical types of losses can be studied, and influences of or chemical reactions at high temperatures cannot be included.

A second frequently used approach is to study metal losses in slags by industrial and/or lab scale sampling procedures using industrial and/or synthetic slags. $[26,28,58,73,74]$ This approach allows to monitor the copper losses (both chemical and mechanical) within processes taking place at high temperature by taking samples of the slag, matte or alloy are taken at high temperature. Profound analyses of the samples, combined with mass balances and thermodynamic analyses have provided valuable insights. Note that attention should be paid to the fact that slow cooling of the samples can influence the microstructure of the samples, as illustrated by the observations by Jalkanen et al. [28]: even when the slag is quenched properly, a major part of the dissolved copper in the slag precipitates as metallic copper from the slag, present as finely dispersed copper droplets. Imris et al. [26] studied copper losses in slags of the smelting and converting process by comparing thermodynamic calculations with microscopic examination and industrial data. Genevski et al. [74] studied slag melts obtained from flash smelting furnace operations and these industrial slag samples (air and nitrogen cooled) were used to determine copper losses using microstructural analysis combined with material balance calculations. Takeda [73], on the other hand, used synthetic slag and matte, for which the matte grade was varied. Both phases were melted in a silica or magnesia crucible, which was positioned in a reaction quartz tube under a controlled atmosphere. After the required reaction times, the crucibles were cooled and microscopic analyses and chemical analyses were performed. This approach is very widely applicable and accessible and the use of both industrial and synthetic systems has advantages. However, dynamic phenomena will be more difficult to observe and a critical evaluation of the microstructure is an absolute prerequisite.

A third method is the use of models like phase field models [75,76], computational fluid dynamics [24] or other numerical models [77], simulating the process. Tan [24] used computational fluid dynamics to gain understanding on the importance of the slag layer thickness for the entrainment during skimming. These data were compared with physical models. Pirker [77] applied different numerical models (volume of fluid simulations, super imposed Chimera grids, Lagrangian slag droplets) to study the slag entrainment in liquid metal during tapping processes. The use of models and simulations allows to model processes, in which different important parameters are variable to a very large extent. The combination of models with experimental insights can be a powerful tool.

A fourth method is the use of in-situ X-ray imaging, to monitor the behaviour of slag and alloy at higher temperatures. Some examples of such set-ups are shown in Fig. 17. Holappa et al. [57] studied the bubble bursting at the iron-slag interface with such a set-up, as explained previously. This technique is very valuable, as the behaviour of the liquid phases can be monitored at high temperatures. It is, however, not applicable for all liquid compositions. The condition to be fulfilled is that one of the liquids present should not absorb the X-rays completely (mostly the slag phase, which will result in light grey colour on the 
images), while the second liquid should absorb the X-rays (mostly the metal phase), resulting in a black colour on the X-ray images. Therefore, not all slag-compositions can be used. The slag, for example, can only contain limited concentrations of $\mathrm{Pb}$. Furthermore, this technique is not widely accessible.

A more recent non-destructive technique is 3D X-ray computed tomography (CT) with short analysis time and limited sample preparation [78]. The opaque materials sample, positioned between a X-ray source and a detector, is scanned $360^{\circ}$ around in small steps and in every step, a projection of the linear attenuation coefficients is measured. The reconstruction of the samples is based on a mathematical formalism known as the Radon transform and its mathematical framework [79]. The different mineral phases in the sample have a different linear attenuation coefficient $\mu\left(\mathrm{cm}^{-1}\right)$, which depends on the electron density, the effective atomic number of the material and the energy of the $\mathrm{X}$-ray beam. Wang et al. already used this technique to characterize copper slags $[80,81]$. This technique, however, as it uses Xrays, cannot characterize slags with a high lead concentration.

Despite the large efforts and the big variety in developed experimental techniques, no specific experimental methodology or set-up was available previously to study the phenomenon of the attachment of copper droplets to spinel solids in slags. Recently, however, De Wilde et al. $[43,60]$ developed a specific methodology to study this type of metal losses in slags. They approached the industrial problem with two complementary experimental methodologies. On the one hand, the interaction between the copper droplets and spinel particles was investigated separately with sessile drop experiments between a spinel substrate and copper and/or slag phases. On the other hand, a method was developed to study the attachment of the droplets in the presence of a surrounding slag system with the use of an industrially relevant synthetic slag system. The latter type of experiments gives the opportunity to obtain a better insight on factors like settling time or slag height and verify the observations with those obtained with the first method.

\section{Slag-cleaning operations}

From the previous sections, it can be concluded that the main strategies for minimizing the amount of metal lost in the disposal of the slag are: [7]

- Minimizing the mass of slag generated (minimizing the mass of the slag generated, can be achieved in practice by fluxing as little as possible or not at all.)

- Minimizing the percentage of metal in the slag can be reached by: $[7,33]$

o Maximizing slag fluidity (avoiding excessive solid particles and keeping the slag warm enough)

o Maximizing the surface tension of the slag

o Minimizing the density of the slag

0 Providing enough $\mathrm{SiO}_{2}$ (increasing the immiscibility between slag and matte)

0 Providing a settling zone inside the furnace

o Avoiding tapping of the matte with slag,...

- $\quad$ Processing the slag in a separate step to recover the metal as much as possible (by pyrometallurgical processing and settling or minerals processing of solidified slag). Some of the possible slag-cleaning operations will be summarized in this section. [28]

The metal extraction from slags during slag-cleaning demands time and additional processing costs which should be minimized. [82]

In certain cases, however, metal losses can be inevitable due to furnace operations. [52] Especially if one considers the fact that producing higher-grade mattes in the smelter increases heat generation, reducing 
fuel costs. It also decreases the amount of $S$ to be removed during subsequent converting, hereby decreasing converting requirements. The only drawback of this way of working is the fact that when the matte grade rises (above 60wt\%), the $\mathrm{Cu}$ concentration in the slag increases rapidly. [7] Slags are usually used for construction purposes, road construction and dike fortifications. But it is also used as an aggregate in hydraulic cement and concrete. Several other opportunities are available for clean slags: granulated fayalite slags are widely used for abrasive cleaning of steel in ships and bridges, granulated forsterite slags are used as mould sand in producing aluminium castings and finely ground granulated slag has been found to have pozzolanic properties and has been used for consolidation of mine backfill. [83] However, as leaching of any metals by rain would have serious consequences, it is necessary to use 'clean' slags for these construction purposes. Moreover, the metal value in these slags is too high to justify the common practice of discarding them.

To encourage suspended droplets to settle, conditions such as a low viscosity slag, low turbulence, a long residence time and a thin slag layer are required. These conditions are often difficult to obtain in a smelting vessel; the necessary residence time, in particular, is hard to acquire [7]. This is why slag cleaning is often carried out in a separate operation. [9] The slag cleaning furnaces have two purposes: allowing suspended droplets to finish settling and facilitating the reduction of dissolved $\mathrm{Cu}$ oxide. After pyrometallurgical settling, the amount of $\mathrm{Cu}$ in the slag is reduced to $0.7-1 \mathrm{wt} \%$. [7]

Several possibilities exist for treating the slag, such as milling, pyrometallurgical treatment (contact the slag with carbonaceous reductant), electric furnace cleaning (traditional slag cleaning processes based on gravitational settling) [2,9], froth flotation (no recovery of dissolved valuable metals) [28], vibratory settling of metals from the slag, centrifugation of the slags, recovery by addition of molten FeS or CaS, addition of cast iron rich in carbon, fuming (blowing the molten slag with a coal-air mixture, reducing the nonferrous elements by the $\mathrm{CO}$ formed and collecting the volatile elements), electrolysis of copper slags, hydrometallurgical treatments of slags and magnetic separation of slags [3]. All these slag cleaning processes can be divided into two types: pyrometallurgical reduction and settling (performed in an electric or fuel fired slag-cleaning furnace) and minerals processing of solidified slag (including crushing, grinding and froth flotation, to recover $\mathrm{Cu}$ from the slag). [7] The following paragraphs discuss some of these treatments in more detail.

\subsection{Mineral processing}

It is possible to remove Cu from convertor slags by slowly solidifying, crushing and grinding it. Due to the slow cooling, a lot of the dissolved $\mathrm{Cu}$ (oxidic form) reacts with $\mathrm{FeO}$, forming $\mathrm{Fe}_{3} \mathrm{O}_{4}$ and metallic $\mathrm{Cu}$. This reaction can lower the dissolved $\mathrm{Cu}$ content of the converter slag to below $0.5 \mathrm{wt} \%$. After the slag has solidified, the exsolved copper and suspended matte particles can be removed from the slag by froth flotation. Successful minerals processing of slags depends on whether or not the precipitated grains of matte and metallic $\mathrm{Cu}$ are large enough to be liberated by crushing and grinding. This can be accomplished by cooling the slag slowly to about $1000^{\circ} \mathrm{C}$ and then naturally to ambient temperature. Afterwards, the same processing can be used as for manipulating ores. [7]

\subsubsection{Froth flotation}

Froth flotation separates hydrophobic materials from hydrophilic. The ore mixture or milled slag is mixed with water, forming a slurry. A surfactant is added to make the desired mineral hydrophobic. In the frotation cells or tanks, the slurry is aerated to produce bubbles, to which the hydrophobic particles attach. The bubbles and attached particles rise to the surface, forming the froth, which is removed and thus a concentrate of the mineral is obtained. [84] 
Metallic and sulphide particles can be flotated from ground slag. However, metals dissolved in slag are not recoverable by froth flotation. Moreover, too small particles not exposed in the grinding of slag are lost with flotation residue. The concentrate from slag flotation can then be re-circulated back to the smelting stages. [28]

\subsubsection{Leaching}

Another option to extract metals from copper slags is leaching. Frequently applied leachants are ferric chloride with or without prior reduction, sulphuric acid, hydrochloric acid, ammonia, cyanide and so on. At first, cyanide was the most frequently used leachant, but it was replaced by other leachants due to environmental issues. [22] A lot of research has been performed in order to optimize leaching conditions such as temperature, the concentration of sulphuric acid, the leaching time, particle size and so on. [8588] In general, higher molarities of the leaching acid, higher interaction times and higher temperatures increase the recovery. For the recovery of copper, Basir et al. [85] observed a plateau at 10M (acid molarity) for hydrochloric acid. For sulphuric acid and ammonia, a steep increase in recovery was noted until $4 \mathrm{M}$, a further increase in acidic molarity caused a much smaller improvement in efficiency. For hydrochloric acid and ammonia, a strong increase in the amount of extraction was visible for a temperature up to $90^{\circ} \mathrm{C}$. [85] Banza et al. [87] observed a significant improvement in the leaching recovery for copper using $\mathrm{H}_{2} \mathrm{SO}_{4}$ when a temperature increase from $24^{\circ} \mathrm{C}$ to $60^{\circ} \mathrm{C}$ and a 60 minute interaction time was applied. Additional measures such as the addition of hydrogen peroxide $\left(\mathrm{H}_{2} \mathrm{O}_{2}\right)$, pressure leaching or leaching in $\mathrm{Cl}_{2} / \mathrm{Cl}^{-}$system have proved to be able to significantly raise the efficiencies of leaching. $[85,89,90]$ The addition of hydrogen peroxide to leachants increases the rate of copper dissolution. The decomposition reaction of hydrogen peroxide in water and nascent oxygen is catalyzed by the metal to be dissolved. Subsequently, metal oxide is formed, which reacts with the acid or ammonia. [85] Herreros et al. [89] proved that chlorine leaching $\left(\mathrm{Cl}_{2} / \mathrm{Cl}^{-}\right.$from reaction of $\mathrm{NaOCl}$ and $\left.\mathrm{HCl}\right)$ of copper from slags containing metallic copper, copper sulphide minerals and complex sulphides with very small sizes was successful.

\subsubsection{Roasting}

Roasting is also applied to clean industrial copper slags. Roasting is used to convert the metals in copper slag into a desired form which can be separated from the slag. A possibility is reductive roasting of metals in the slags into free metals. Afterwards, this is combined with flotation or leaching for separation of the metals from the slag. Another more effective method is sulphating roasting, in which copper in various forms is converted into soluble sulphates through a series of chemical reactions at $200-600^{\circ} \mathrm{C}$ by addition of sulphide or sulphate agents. The soluble sulphates are dissolved in water and separated from the slag. Altundogan et al. [91] yielded a high copper recovery of $93 \%$ due to roasting of a converter slag with ferric sulphate and subsequently leaching with water.

\subsection{Pyrometallurgical treatment}

The El Teniente slag cleaning furnace process for example, reduces the magnetite and copper content in molten slag (with 7-10wt\% $\mathrm{Cu}$ and $12-16 \mathrm{wt} \% \mathrm{Fe}_{3} \mathrm{O}_{4}$ in it) by injection of solid, liquid or gaseous reductants directly into the molten slag through specially designed tuyeres, followed by a sedimentation stage. The reduction of the magnetite decreases the viscosity of the slag and enhances the settling of the created copper enriched phase. Copper matte inclusions are formed with sizes varying between $\mu \mathrm{m}$ and $\mathrm{mm}$. Bigger inclusions settle down, and collect smaller inclusions due to collisions and coalescence. However, gravitational coalescence only enables partial removal of small inclusions and overall metal recovery is 
usually not satisfactory. [25] The settling of these inclusions is strongly influenced by the slag motion, which is mainly induced by convection due to temperature gradients in the molten slag. The copper concentration in the slag is decreased to less than $1 \mathrm{wt} \%$, thus the slag can be discarded. [26]

The reduction of magnetite can be performed by skimming the converter slag into a ladle containing coal or placing green timber on top of the skimmed slag before returning the converter slag to the smelting stage. $[3,29]$ An even better alternative is the reduction with $\mathrm{CaC}_{2}$ proposed by Zander et al. [2]: it has a five times higher rate of reduction compared to cokes and the dissolution of $\mathrm{CaO}$ decreases the slag viscosity and improves the settling velocity of the copper containing droplets. The influence of additives is not significant, unless the bath is also stirred. Without the bath movement the reduction reactions with the slag take more time compared to adding the reductant under stirring conditions. [2]

\subsubsection{Additional stirring}

Zander et al. [2] investigated the influence of different stirring conditions on the settling behaviour of metallic/matte droplets. It was concluded that heating up the slag to above $1500^{\circ} \mathrm{C}$ (overheating of the slag) with moderate stirring achieves a maximum decrease of $50 \%$ of the copper content. Without stirring a cleaning rate of $18 \% \mathrm{Cu}$ was obtained. Marginal stirring yields a cleaning rate of $18 \% \mathrm{Cu}$ compared to the feedstock. Turbulent stirring conditions lead to a cleaning of $23 \% \mathrm{Cu}$. Strong turbulence in the melt, by flushing gas injection, hinders the settling of the copper particles. In contrast to that, the gas injection has a positive effect on the lead cleaning, this is due to partial evaporation. By using $\mathrm{CaC}_{2}$ as a reducing agent under optimal stirring conditions, a maximal cleaning rate can be achieved. Zander et al. [2] also observed that the addition of $\mathrm{CaO}, \mathrm{MgO}$ and $\mathrm{CaF}_{2}$ as fluxes decreased the viscosity a lot and decreased the copper content. On a larger scale, the slag stirring can be produced by an electromagnet on the outside of the reactor.

\subsubsection{Electrical fields}

The settling of mechanically entrained droplets in liquid slags can be affected by electric fields. This is due to electrocapillary motion phenomena and it can be used to enhance the recovery of suspended droplets. [44] The speed generated by electrocapillary motion is of the order of $\mathrm{cm} / \mathrm{s}$, which yields high processing rates compared to traditional gravitational settling. [52] The drop migration rate due to electrocapillary motion is proportional to the electric field strength and the drop radius. [44]

Warczok and Riveros [44] found that an electric field can increase the settling rate of $5 \mathrm{~mm}$-diameter copper drops up to 3 times. It can even cause levitation of the droplets. It should be noted, however, that the enhanced settling due to electric field decreases with increasing drop size or increasing $\mathrm{Cu}_{2} \mathrm{O}$ content of the slag (because this affects the surface charge density of the drop). [44] It should also be noted that the migration rate of solid phase inclusions differs from those of liquid phase inclusions. It seems that the droplets of matte or metal follow a migration path that is not obvious. By determining the interfacial tension of the metals or matte droplet-electrolyte as a function of electric potential, it is possible to predict the direction of migration of these droplets. Drop motion is driven by the interaction between the interfacial tension and the electric field. The interfacial tension is a function of the droplet and slag composition and of the electro-kinetics of the redox reactions on the surface. [52] Choo and Toguri [52] also observed that droplets can migrate to either electrode. Different droplets even migrated past each other across the surface of the slag. Such independent motions suggest the possibility of specific control of the droplet's migration behaviour which can be used in slag cleaning operations.

\section{Summary}


It was illustrated that metal losses in slags are a widely occurring problem in different metal industries, both ferrous and non-ferrous. At this moment, it is generally accepted that there are two types of losses: chemical losses and mechanical losses. Chemical losses refer to the dissolution of metal in the slag. Mechanical losses are entrained metal droplets which do not settle and do not end up in the underlying matte or metal phase.

The amount of chemical losses is thermodynamically determined, but there is no clear consensus on the form of the dissolved metal in the slag. For the mechanical entrainment of metals in slag, on the other hand, three main reasons have been discussed in previous reviews already:

1. Entrainment due to charging of the furnace or tapping of the slag

2. Precipitation of copper from slag due to temperature or oxygen level gradients within the furnace or due to chemical reactions

3. Sulphur dioxide gas, produced in the matte phase, or other gas phases dispersing the matte into the slag as the gas crosses the matte-slag interface

A fourth reason, however, has only been studied recently in a fundamental way to obtain knowledge regarding the mechanisms responsible for the interaction: the attachment of matte/metal droplets to solid particles present in the slag phase which hinder their settling. The results of a combined approach of experiments and modelling work point towards a reactive origin of the attachment of the metal droplets to the solids spinel particles.

An overview of the several experimental set-ups to investigate metal losses in slags was also presented, as well as an overview of the existing slag-cleaning operations. These slag-cleaning operations remain operational in industry at present, because it is not possible to completely avoid metal losses, either chemical or mechanical.

\section{Acknowledgements}

I. Bellemans holds a PhD fellowship of the Research Foundation - Flanders (FWO).

\section{References}

[1] Heulens J. Isothermal Crystallization of Metallurgical Slags: Phase Field Simulations Combined with In Situ Experiments (Isotherme kristallisatie van metallurgische slakken: faseveldsimulaties in combinatie met in situ experimenten). PhD thesis. KU Leuven, 2011.

[2] Zander M, Friedrich B, Degel R, Kleinschmidt G, Hoppe M, Schmidl J. Improving copper recovery from production slags by advanced stirring methods. Proc. EMC 2011, Düsseldorf, Germany: 2011, p. 18195.

[3] Yannopoulos J. Control of copper losses in reverberatory slags - a literature review. Can Metall Q 1970;10:291-307.

[4] Calvo FA, Ballester A. Lead losses in the slag of a reduction melting furnace. Erzmetal 1986;6:282-7.

[5] Calvo FA, Ballester A. The settling of metallic lead from lead blast furnace slag. Metall Trans $B$ 1986;17:267-70. doi:10.1007/BF02655073.

[6] Nkohla MA. Characterization of ferrochrome smelter slag and its implications in metal accounting. Cape Peninsula University of Technology, 2006.

[7] Davenport WG. Extractive metallurgy of copper. Fourth edition. Kidlinghton: Oxford: Elsevier Science Ltd; 2002.

[8] Yazawa A. Thermodynamic considerations of copper smelting. Can Metall Q 1974;13:443-53. 
[9] Mackey PJ. The Physical Chemistry of Copper Smelting Slags -A Review. Can Metall Q 1982;21:22160. doi:10.1179/cmq.1982.21.3.221.

[10] World Bank Group. Lead and Zinc Smelting 1998.

[11] Toscano P, Utigard A. Nickel, copper, and cobalt slag losses during converting. Metall Mater Trans B 2003;34:121-5. doi:10.1007/s11663-003-0062-5.

[12] Fundamentals of Steel Product Physical Metallurgy. 1st edition. United States: Assn of Iron \& Steel Engineers; 2011.

[13] Vermaak MKG. Vanadium recovery in the electro-aluminothermic production of ferrovanadium. Dissertation (M Eng (Metallurgical Engineering)). University of Pretoria, 2007.

[14] Vermaak MKG, Pistorius PC. Equilibrium slag losses in ferrovanadium production. Metall Mater Trans B 2000;31:1091-7. doi:10.1007/s11663-000-0084-1.

[15] Solar MY. Mechanical slag losses in laterite smelting - nickel. Proc. Pyrometallurgy Nickel Cobalt 2009, Montreal, Canada: The Metallurgical Society of CIM; 2009, p. 277-92.

[16] Choi N, Cho WD. Distribution behavior of cobalt, selenium, and tellurium between nickel-copperiron matte and silica-saturated iron silicate slag. Metall Mater Trans B 1997;28:429-38. doi:10.1007/s11663-997-0109-0.

[17] Gudim YA, Ovchinnikov SG, Zinurov IY. Metal losses during steelmaking in arc furnaces and methods for their decreasing. Russ Metall Met 2011;2011:495-8. doi:10.1134/\$0036029511060103.

[18] Alaetting Mustafa Aksoy. An investigation of copper losses in copper reverberatory slags. PhD dissertation. Department of Metallurgy, Massachusetts institute of technology, 1943.

[19] Sridhar R, Toguri JM, Simeonov S. Copper losses and thermodynamic considerations in copper smelting. Metall Mater Trans B 1997;28:191-200. doi:10.1007/s11663-997-0084-5.

[20] USGS Minerals Information: Copper n.d. https://minerals.usgs.gov/minerals/pubs/commodity/copper/index.html\#mcs (accessed July 9, 2017).

[21] Warczok A, Riveros G. Slag cleaning in crossed electric and magnetic fields. Miner Eng 2007;20:3443. doi:10.1016/j.mineng.2006.04.007.

[22] Shen HT, Forssberg E. An overview of recovery of metals from slags. Waste Manag 2003;23:933-49. doi:10.1016/s0956-053x(02)00164-2.

[23] Zivkovic I, Mitevska N, Mihajlovic I, Nikolic D. The influence of the silicate slag composition on copper losses during smelting of the sulphide concentrates. J Min Metall Sect B-Metall 2009;45:23-34. doi:10.2298/jmmbb0901023z.

[24] Tan PF. Modeling and control of copper loss in smelting slag. Jom 2011;63:51-7. doi:10.1007/s11837-011-0207-y.

[25] Degel R, Oterdoom H, Kunze J, Warczok A, Riveros G. Latest results of the slag cleaning reactor for copper recovery and its potential for the PGM industry. Proc. Third Int. Platin. Conf. Platin. Transform., The Southern African Insititute of Mining and Metallurgy, Sun City, South Africa: The Southern African Institue of Mining and Metallurgy; 2008, p. 197-202.

[26] Imris I, Sánchez M, Achurra G. Copper losses to slags obtained from the El Teniente process. Miner Process Extr Metall 2005;114:135-40. doi:10.1179/037195505X49769.

[27] Cardona N, Coursol P, Mackey PJ, Parra R. Physical chemistry of copper smelting slags and copper losses at the Paipote smelter Part 1-Thermodynamic modelling. Can Metall Q 2011;50:318-29. doi:10.1179/000844311x13112418194761.

[28] Jalkanen H, Vehviläinen J, Poijärvi J. Copper in solidified copper smelter slags. Scand J Metall 2003;32:65-70. doi:10.1034/j.1600-0692.2003.00536.x.

[29] Maruyama T, Furui N, Hamamoto M, Sunamoto T. The copper loss in slag of flash smelting furnace in Tamano smelter. Proc. Yazawa Int. Symp., 2003, p. 337-47. 
[30] Nagamori M. Metal loss to slag .2. Oxidic dissolution of nickel in fayalite slag and thermodynamics of continuous converting of nickel-copper matte. Metall Trans 1974;5:539-48. doi:10.1007/bf02644647.

[31] Wang SS, Santander. N. H, Toguri JM. Solublity of nickel and cobalt in iron silicate slags. Metall Trans 1974;5:261-5.

[32] Toguri JM, Santander NH. Distribution of copper between Cu-Au alloys and silica-saturated fayalite slags. Metall Trans 1972;3:586-8.

[33] Kim HG, Sohn HY. Effects of $\mathrm{CaO}, \mathrm{Al2O}$, and $\mathrm{MgO}$ additions on the copper solubility, ferric/ferrous ratio, and minor-element behavior of iron-silicate slags. Metall Mater Trans B 1998;29:583-90. doi:10.1007/s11663-998-0093-z.

[34] Gilchrist JD. Extraction metallurgy. 2nd ed. Pergamon Press; 1979.

[35] Richardson FD, Billington JC. Copper and silver in silicate slags. Trans Inst Min Met 1956;65:273-297.

[36] Sehnàlek F, Imris I. Slags from continuous copper production. Proc. IMM 1972 Adv. Extr. Metall. Refin., London: 1972, p. 39-62.

[37] Nagamori M. Metal loss to slag.1. Sulfidic and oxidic dissolution of copper in fayalite slag from lowgrade matte. Metall Trans 1974;5:531-8. doi:10.1007/bf02644646.

[38] Suh I-K, Waseda Y, Yazawa A. Some interesting aspects of non-ferrous metallurgical slags. High Temp Mater Process 1988;8:65-88.

[39] Gaskell D, Palacois J, Somsiri C. The physical chemistry of copper mattes. Proc. Elliot Symp. Chem. Process Metall., Cambridge, United Kingdom: 1990.

[40] Victrovitch G. Precipitation of copper on cooling of iron silicate slags. Proc. XIM Conf. Metall. Int. Symp. Metall. Slags, Nova Scotia, Canada: 1980.

[41] Imris I, Rebolledo S, Sanchez M, Castro G, Achurra G, Hernandez F. The copper losses in the slags from the El Teniente process. Can Metall Q 2000;39:281-9.

[42] Fagerlund KO, Jalkanen H. Some aspects on matte settling in copper smelting. In: Diaz C, Landolt C, Utigard T, editors. Proc. Smelt. Technol. Dev. Process Model. Fundam., vol. VI-Smelting, Technology Development, Process Modeling and Fundamentals-, Phoenix, Arizona: 1999, p. 539-51.

[43] Bellemans I. Towards a methodology to study the interaction between $\mathrm{Cu}$ droplets and spinels. Masters thesis. Ghent University, 2013.

[44] Warczok A, Riveros G. Electromagnetic buoyancy force of copperinclusions in a liquid slag. Proc. ConametSAM-Simp. Mater., Santiago, Chile: 2002.

[45] Lebedev AA. Stokes' law as applied to liquid balls. J Russ Phys Chem Soc Part Phys 1916;48:97-131.

[46] Dukhin SS, Kretzchmar G, Miller B. Dynamics of adsorption at liquid interfaces. 1st ed. Elsevier; 1995.

[47] Poggi D, Minto R, Davenport W. Mechanisms of metal entrapment in slags. J Met 1969;21:40-.

[48] Seok SH, Jung SM, Lee YS, Min DJ. Viscosity of Highly basic Slags. Isij Int 2007;47:1090-6. doi:10.2355/isijinternational.47.1090.

[49] Lau C, Mukasyan AS, Varma A. Materials synthesis by reduction-type combustion reactions: Influence of gravity. Proc. Combust. Inst., vol. 29, 2002, p. 1101-8. doi:10.1016/s15407489(02)80139-0.

[50] Fagerlund $\mathrm{KO}$, Jalkanen $\mathrm{H}$. Microscale simulation of settler processes in copper matte smelting. Metall Mater Trans B-Process Metall Mater Process Sci 2000;31:439-51. doi:10.1007/s11663-0000150-8.

[51] Ip SW, Toguri JM. Entrainment behavior of copper and copper matte in copper smelting operations. Metall Trans B 1992;23:303-11. doi:10.1007/BF02656285.

[52] Choo RTC, Toguri JM. The role of interfacial tension in high temperature nonferrous metallurgy. In: Lakshmanan VI, Bautista RG, Somasundaran P, editors. Proc. Symp. Emerg. Sep. Technol. Met. Fuels, Palm Coast, Florida, USA: 1993, p. 153-67. 
[53] Liow JL, Juusela M, Gray NB, Sutalo ID. Entrainment of a two-layer liquid through a taphole. Metall Mater Trans B - Process Metall Mater Process Sci 2003;34:821-32. doi:10.1007/s11663-003-00888.

[54] Gaye H, Lucas LD, Olette M, Riboud PV. Metal-slag interfacial properties : equilibrium values and "dynamic" phenomena. Canedian Metall Q 1984;23:179-91.

[55] Rhamdhani MA, Coley KS, Brooks GA. Role of oxygen in interfacial phenomena during high temperature reactions. In: Irons G, Sun S, editors. Proc. 43th Annu. Coference Metall. CIM, Hamilton, Ontario, Canada: 2004, p. 203-17.

[56] Rhamdhani MA, Brooks GA, Coley KS. Kinetics of metal/slag reactions during spontaneous emulsification. Metall Mater Trans B-Process Metall Mater Process Sci 2005;36:219-27. doi:10.1007/s11663-005-0023-2.

[57] Holappa L, Forsbacka L, Han ZJ. Measuring and modeling of viscosity and surface properties in high temperature systems. Isij Int 2006;46:394-9. doi:10.2355/isijinternational.46.394.

[58] Imris I. Copper losses in copper smelting slags. In: Kongoli F, Itagaki K, Yamauchi C, Sohn HY, editors. Proc. Yazawa Int. Symp., vol. 1 Materials Processing Fundamentals and New Technologies, Sandiego, California, USA: 2003, p. 359-73.

[59] Minto R, Davenport WG. Entrapment and flotation of matte in molten slags. Can Min Metall Bull 1972;65:C36-42.

[60] De Wilde E, Bellemans I, Vervynckt S, Campforts M, Vanmeensel K, Moelans N, et al. Towards a methodology to study the interaction between $\mathrm{Cu}$ droplets and spinel particles in slags. Proc. EMC 2013, vol. 1, 2013, p. 161-74.

[61] De Wilde E, Bellemans I, Campforts M, Khaliq A, Vanmeensel K, Seveno D, et al. Wetting behaviour of $\mathrm{Cu}$ based alloys on spinel substrates in pyrometallurgical context. Mater Sci Technol 2015;31:1925-33. doi:10.1179/1743284715Y.0000000052.

[62] De Wilde E, Bellemans I, Zheng L, Campforts M, Guo M, Blanpain B, et al. Origin and sedimentation of Cu-droplets sticking to spinel solids in pyrometallurgical slags. Mater Sci Technol 2016;32:191124. doi:10.1080/02670836.2016.1151998.

[63] Barker IL, Jacobi JS, Wadia BH. Some notes on Oroya copper slags. Trans Am Inst Min Metall Eng 1957;209:774-80.

[64] Higgins R, Jones TJB. Viscosity characteristics of Rhodesian copper smelting slags. Trans Inst Min Met 1963;82:285-98.

[65] Cardona N, Hernandez L, Araneda E, Parra R. Evaluation of copper losses in the slag cleaning circuits from two Chilean smelters. Proc. Copp. 2010, vol. 7, Hamburg, Germany: GMDB; 2010, p. 2637-54.

[66] De Wilde E, Bellemans I, Campforts M, Guo M, Blanpain B, Moelans N, et al. Sessile drop evaluation of high temperature copper/spinel and slag/spinel interactions. Trans Nonferrous Met Soc China 2016;26:2770-83. doi:10.1016/S1003-6326(16)64344-3.

[67] De Wilde E, Bellemans I, Campforts M, Guo M, Blanpain B, Moelans N, et al. Investigation of HighTemperature Slag/Copper/Spinel Interactions. Metall Mater Trans B 2016;47:3421-34. doi:10.1007/s11663-016-0805-8.

[68] Bellemans I, De Wilde E, Claeys L, De Seranno T, Campforts M, Blanpain B, et al. Investigation of reactive origin for attachment of Cu-droplets to solid particles. Metall Mater Trans B 2017.

[69] Durinck D, Jones PT, Blanpain B, Wollants P. Air-Cooling of Metallurgical Slags Containing Multivalent Oxides. J Am Ceram Soc 2008;91:3342-8. doi:10.1111/j.1551-2916.2008.02597.x.

[70] Kim H, Ozturk B, Fruehan RJ. Slag-metal separation in the blast furnace trough. Isij Int 1998;38:4309. doi:10.2355/isijinternational.38.430.

[71] Savolainen J, Fabritius T, Mattila O. Effect of Fluid Physical Properties on the Emulsification. Isij Int 2009;49:29-36. 
[72] Akdogan G, Eric RH. Physical modelling of slag-metal dispersion. J South Afr Inst Min Metall 2004;104:589-95.

[73] Takeda Y. Thermodynamic evaluation of copper loss in slag equilibrated with matte. In: Kongoli $F$, Itagaki K, Yamauchi C, Sohn HY, editors. Proc. Yazawa Int. Symp., vol. 1 Materials Processing Fundamentals and New Technologies, Sandiego, California, USA: 2003, p. 341-57.

[74] Genevski K, Stefanova V. Dispersed matte droplets in industrial slag melts from flash smelting furnace. Can Metall Q 2008;47:51-8.

[75] Bellemans I, Moelans N, Verbeken K. Phase field modelling of the attachment of metallic droplets to solid particles in liquid slags: Influence of interfacial energies and slag supersaturation. Comput Mater Sci 2015;108, Part B:348-57. doi:10.1016/j.commatsci.2015.03.019.

[76] Bellemans I, De Wilde E, Moelans N, Verbeken K. Phase field modelling of the attachment of metallic droplets to solid particles in liquid slags: Influence of particle characteristics. Acta Mater 2015;101:172-80. doi:10.1016/j.actamat.2015.08.074.

[77] Pirker S. Towards Efficient Modelling of Slag Entrainment during Metallurgical Processes. Steel Res Int 2010;81:623-9. doi:10.1002/srin.201000084.

[78] Miller JD, Lin CL. Three-dimensional analysis of particulates in mineral processing systems by cone beam X-ray microtomography. Miner Metall Process 2004;21:113-24.

[79] Dhawan N, Safarzadeh MS, Miller JD, Moats MS, Rajamani RK, Lin C-L. Recent advances in the application of X-ray computed tomography in the analysis of heap leaching systems. Miner Eng 2012;35:75-86. doi:10.1016/j.mineng.2012.03.033.

[80] Wang X, Geysen D, T SVP, D'Hoker N, Gerven TV, Blanpain B. Characterization of Copper Slag. REWAS 2013, Springer, Cham; 2013, p. 54-68. doi:10.1007/978-3-319-48763-2_7.

[81] Wang X, Geysen D, Tinoco SVP, D'Hoker N, Gerven TV, Blanpain B. Characterisation of copper slag in view of metal recovery. Miner Process Extr Metall 2015;124:83-7. doi:10.1179/1743285515Y.0000000004.

[82] Sudbury MP, Kemp DJ. The properties and uses of granulated non ferrous slags. Proc. TMS 2006, San Antonio, Texas, United States: Minerals and Materials Society; 2006, p. 611-20.

[83] Sánchez M, Sudbury M. Physicochemical characterization of copper slag and alternatives of friendly environmental management. J Min Metall Sect B Metall 2013;49:161-8. doi:10.2298/JMMB120814011S.

[84] Fuerstenau MC, Jameson GJ, Yoon R-H. Froth Flotation: A Century of Innovation. SME; 2007.

[85] Basir SMA, Rabah MA. Hydrometallurgical recovery of metal values from brass melting slag. Hydrometallurgy 1999;53:31-44.

[86] Kuo C-Y, Wu C-H, Lo S-L. Removal of copper from industrial sludge by traditional and microwave acid extraction. J Hazard Mater 2005;120:249-56. doi:http://dx.doi.org/10.1016/j.jhazmat.2005.01.013.

[87] Banza AN, Gock E, Kongolo K. Base metals recovery from copper smelter slag by oxidising leaching and solvent extraction. Hydrometallurgy 2002;67:63-9. doi:http://dx.doi.org/10.1016/S0304386X(02)00138-X.

[88] Urosevic DM, Dimitrijevic MD, Jankovic; Zoran D. Recovery of copper from copper slag and copper slag flotation tailings by oxidative leaching. Physicochem Probl Miner Process 2015;51:73-82.

[89] Herreros O, Quiroz R, Manzano E, Bou C, Vinals J. Copper extraction from reverberatory and flash furnace slags by chlorine leaching. Hydrometallurgy 1998;49:87-101. doi:10.1016/s0304386x(98)00010-3.

[90] Anand S, Rao KS, Jena PK. Pressure leaching of copper converter slag using dilute sulfuric-acid for the extraction of cobalt, nickel and copper values. Hydrometallurgy 1983;10:305-12. doi:10.1016/0304-386x(83)90061-0. 
[91] Altundogan HS, Tumen F. Metal recovery from copper converter slag by roasting with ferric sulphate. Hydrometallurgy 1997;44:261-7. doi:10.1016/s0304-386x(96)00038-2.

[92] Andrews L. Base metal losses to furnace slag during processing of platinum-bearing concentrates. PhD. University of Pretoria, 2008.

[93] Rhamdhani MA, Coley KS, Brooks GA. Analysis of the source of dynamic interfacial phenomena during reaction between metal droplets and slag. Metall Mater Trans B-Process Metall Mater Process Sci 2005;36:591-604. doi:10.1007/s11663-005-0050-z.

[94] Vervynckt S. Cu smelting and converting technology 2012.

[95] Matsushita T, Watanbe T, Seetharaman S, Mukai S. Interfacial phenomena between molten steel and slag. Proc. VIII Int. Conf. Molten Slag Fluxes Salts, Santiago, Chile: 2009, p. 703-14.

[96] Rogóz K, Sak T, Kucharski M. Investigations on the interfacial tension between the Ag-Te alloy and the sodium carbonate slag with the use of the X-ray technique. Proc. EMC 2011, 2011, p. 1225-34.

\section{Figure captions}

Fig. 1 Copper losses and their economic impact during smelting in seven plants as summarized by Yannopoulos [3]

Fig. 2 Simulation of copper losses in slag at the Flash Smelting Furnace operation at Tamano smelter. The oxide and sulphide losses were calculated using HSC chemistry, the shaded part shows the operation data. The difference between both is attributed to mechanical losses (referred to as suspension loss) [29,92]

Fig. 3 Effect of the temperature, at constant poz, on the solubility of copper in slags [32]

Fig. 4 Relation between amount of $\mathrm{Cu}$ in the slag and the activity of $\mathrm{Cu}$ in the alloy as a function of $\mathrm{p}_{\mathrm{O} 2}$, at constant temperature [32]

Fig. 5 Schematic diagram of calculated oxidic, sulphidic and total dissolved copper in commercial reverberatory slag [38]

Fig. 6 Relation between settling time and particle size by Stokes' equation calculated by Maruyama et al. [29]

Fig. 7 Droplet shape changes during high temperature reactions (a) schematic representation[54]; (b) shape and droplet changes during the reaction between Fe -4 wt \% $\mathrm{Al}(2.34 \mathrm{~g})$ and $\mathrm{CaO}-\mathrm{SiO}_{2}-\mathrm{Al}_{2} \mathrm{O}_{3}$ at $1650^{\circ} \mathrm{C}$ [93]

Fig. 8 (a) X-ray images showing bursting and detaching of a gas bubble from the iron-slag interface (b) X-ray images showing the mechanism of iron droplet entrainment into slag [57] 
Fig. 9 Proposed mechanisms for the formation of jet and film droplets in the slag when a gas bubble passes through the iron/slag interface [57]

Fig. 10 Interactions between a gas bubble and liquid droplets in a continuous phase: (a) a film of the underlying phase $\left(L_{2}\right)$ is formed on the gas bubble, (b) droplets of the underlying phase $\left(L_{2}\right)$ are scattered in the upper liquid $\left(L_{1}\right)$, and $(c)$ attachment of the droplets of the underlying phase $\left(L_{2}\right)$ to the bubble through contact [59]

Fig. 11 Slag with 3.8 wt\% lead: (M) Magnetite, (P) metallic lead (magnification $x 400$ ) [4]

Fig. 12 SEM backscattered electron images of slag containing metallic droplets [6] (the scale bar in the figure represents $10 \mu \mathrm{m}$ )

Fig. 13 Left: slag at $1200^{\circ} \mathrm{C}$ contains $2 \%$ spinels (with Fe and Zn); Right: slag at $1140^{\circ} \mathrm{C}$ contains $10 \%$ spinels which entrain some Cu drops [94]

Fig. 14 (a) Copper content in slag and matte versus magnetite content in slag at $1250^{\circ} \mathrm{C}$. [26] (b) Special 24 hour industrial test in la Oroya smelter [3,63]

Fig. 15 Detailed microstructures (LOM) of sticking droplets (Cu-Pb) onto (Fe-Zn-Al-O) spinel particles present in slag obtained by melting a mixture of $1.4 \mathrm{wt} \% \mathrm{Al}_{2} \mathrm{O}_{3}-2 \mathrm{wt} \% \mathrm{CaO}-17.2 \mathrm{wt} \%$ $\mathrm{FeO}-45.6 \mathrm{wt} \% \mathrm{PbO}-8.4 \mathrm{wt} \% \mathrm{ZnO}-10.1 \mathrm{wt} \% \mathrm{Cu}-15.2 \mathrm{wt} \% \mathrm{SiO}_{2}$ at $1200^{\circ} \mathrm{C}$ under a $\mathrm{p}_{\mathrm{O} 2}$ of $10^{-7} \mathrm{~atm}$. [61]

Fig. 16 Representative LOM pictures of the upper slag layer at 5, 10, 20, 30, 60 and 90 min after bubbling in slag obtained by melting a mixture of $7.3 \mathrm{wt} \% \mathrm{Al}_{2} \mathrm{O}_{3}-9.8 \mathrm{wt} \% \mathrm{CaO}-19.4 \mathrm{wt} \%$ FeO-39.3wt\% PbO-6.5wt\% $\mathrm{ZnO}-3.9 w t \% \mathrm{Cu}-13.8 w t \% \mathrm{SiO}_{2}$ at $1200^{\circ} \mathrm{C}$ under a $\mathrm{p}_{2}$ of $10^{-7} \mathrm{~atm}$. (SL = slag, SP = Al-Fe-Zn-O spinel solids, Cu-dr = copper-lead alloy droplets) [62]

Fig. 17 (a) X-ray set-up by Ip and Toguri [51] for high-temperature interfacial tension measurements; (b) sample arrangement for interfacial tension measurements in the X-ray set-up of Ip and Toguri [51]; (c) Schematic illustration of X-ray set-up used by Matsushita et al. [95]; (d) Apparatus used by Rogóż et al. [96] for the measurements of the interfacial surface tension in the metal/slag system 


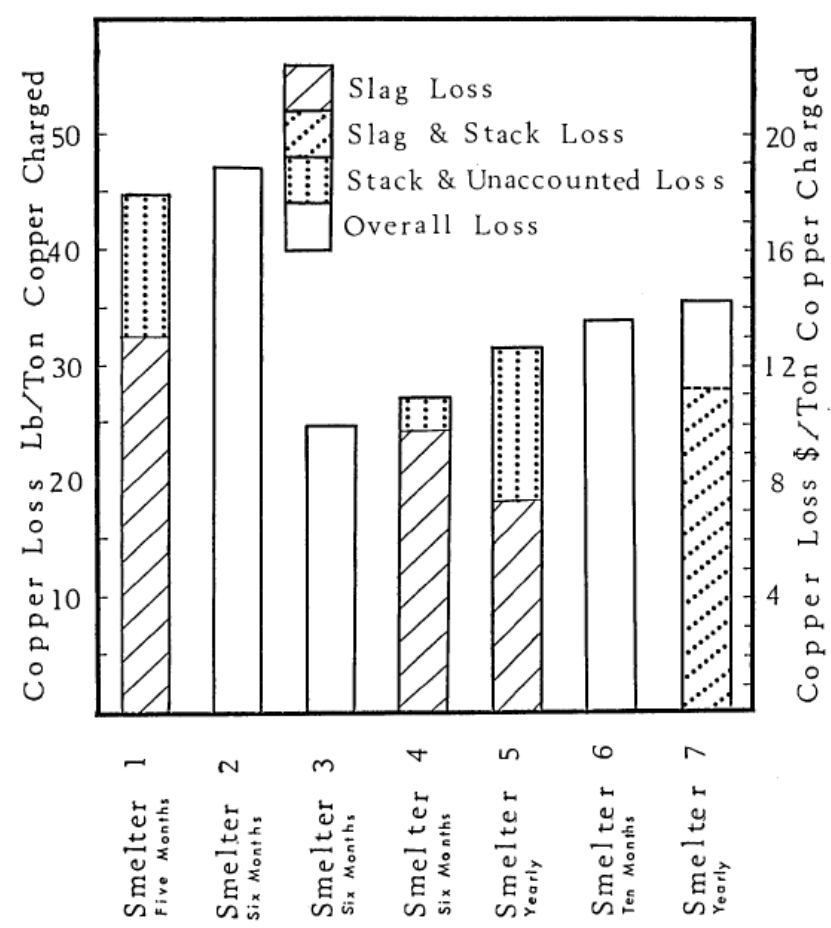

Fig. 1 Copper losses and their economic impact during smelting in seven plants as summarized by Yannopoulos [3] 


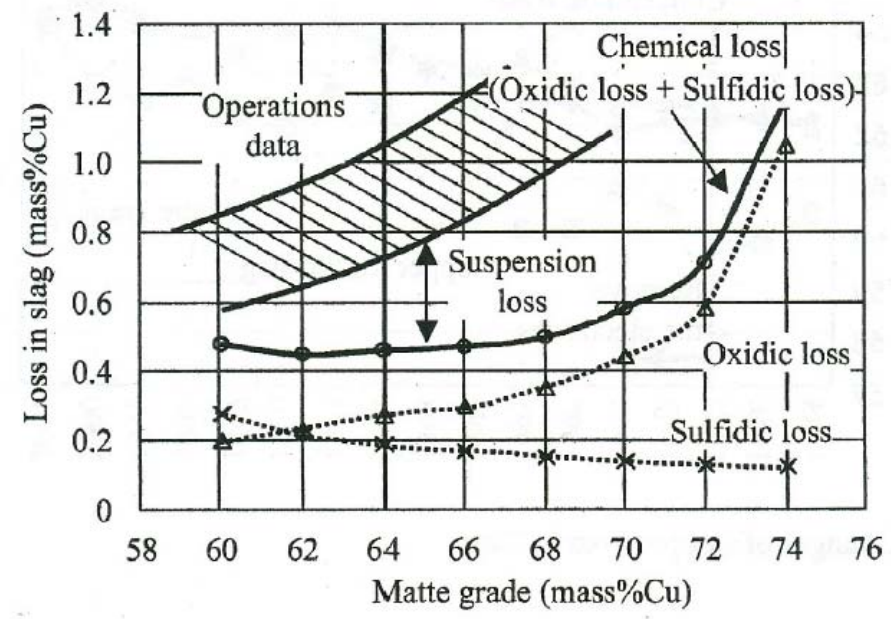

Fig. 2 Simulation of copper losses in slag at the Flash Smelting Furnace operation at Tamano smelter. The oxide and sulphide losses were calculated using HSC chemistry, the shaded part shows the operation data. The difference between both is attributed to mechanical losses (referred to as suspension loss) $[28,29]$ 


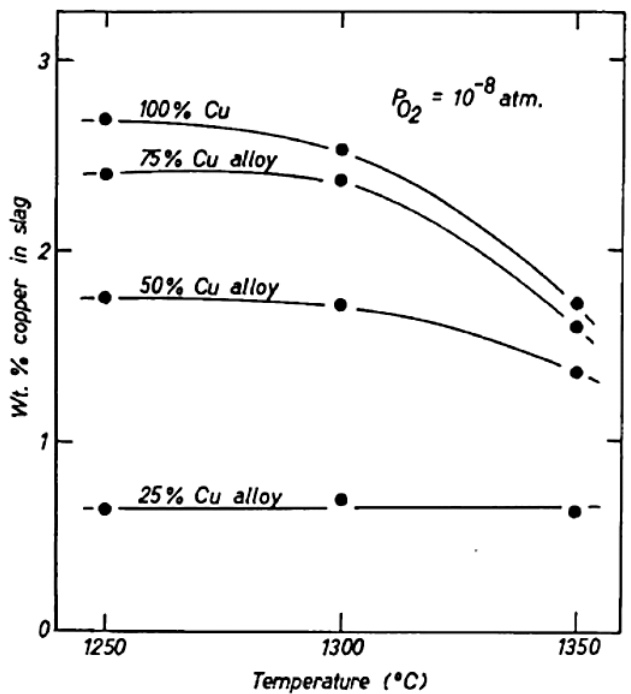

Fig. 3 Effect of the temperature, at constant po2, on the solubility of copper in slags [32] 


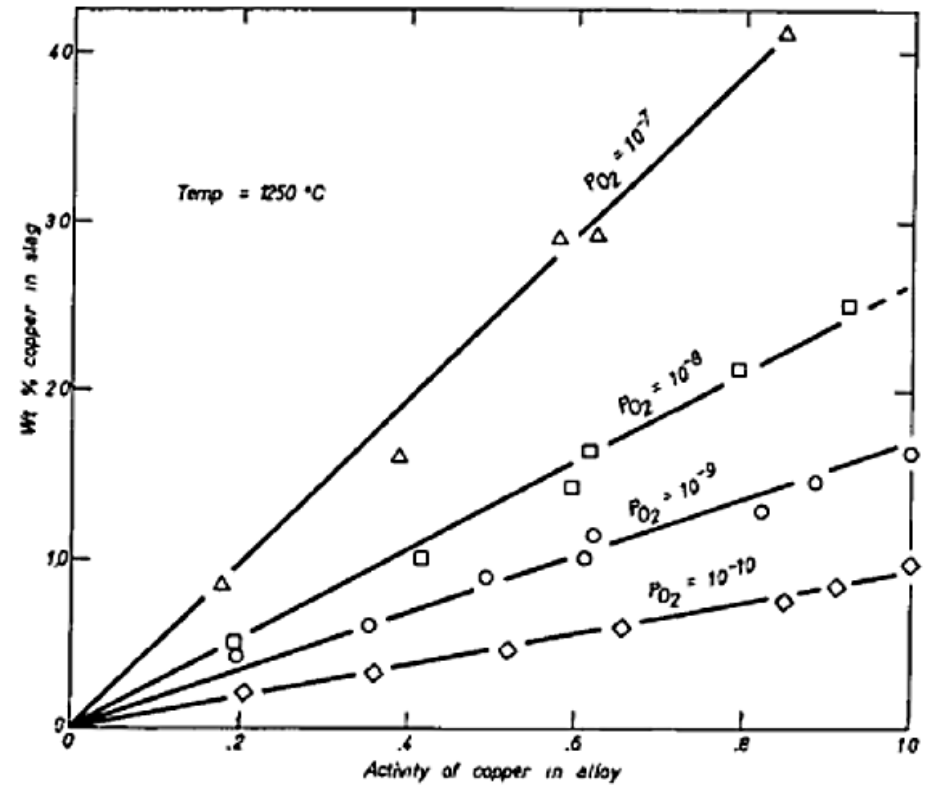

Fig. 4 Relation between amount of $\mathrm{Cu}$ in the slag and the activity of $\mathrm{Cu}$ in the alloy as a function of $\mathrm{p}_{\mathrm{o2}}$, at constant temperature [32] 


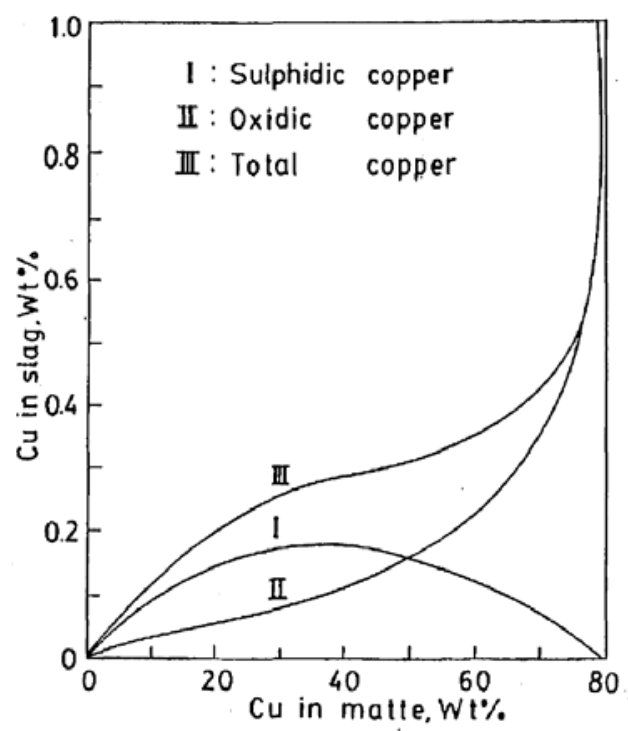

Fig. 5 Schematic diagram of calculated oxidic, sulphidic and total dissolved copper in commercial reverberatory slag [37] 


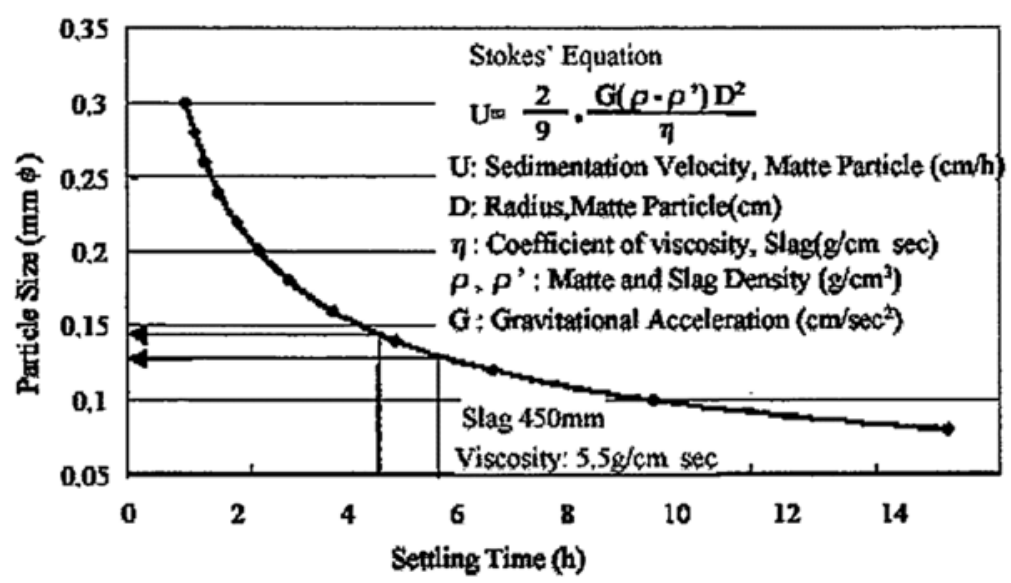

Fig. 6 Relation between settling time and particle size by Stokes' equation calculated by Maruyama et al. [28] 
(a)

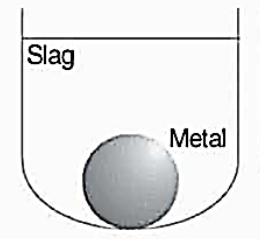

Original shape

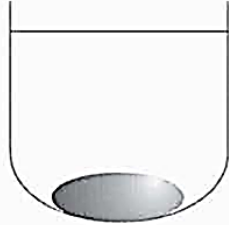

Droplet flattening/ spreading

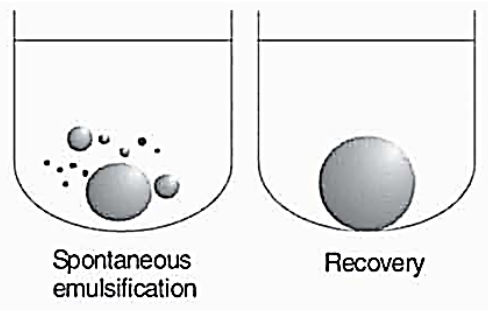

(b)
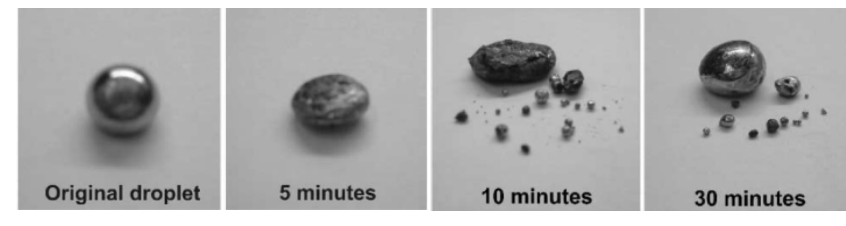

30 minutes

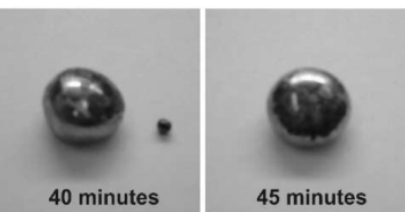

Fig. 7 Droplet shape changes during high temperature reactions (a) schematic representation [54]; (b) shape and droplet changes during the reaction between $\mathrm{Fe}-4 \mathrm{wt} \% \mathrm{Al}(2.34 \mathrm{~g})$ and $\mathrm{CaO}-\mathrm{SiO}_{2}-\mathrm{Al}_{2} \mathrm{O}_{3}$ at $1650^{\circ} \mathrm{C}$ [56] 
(a)
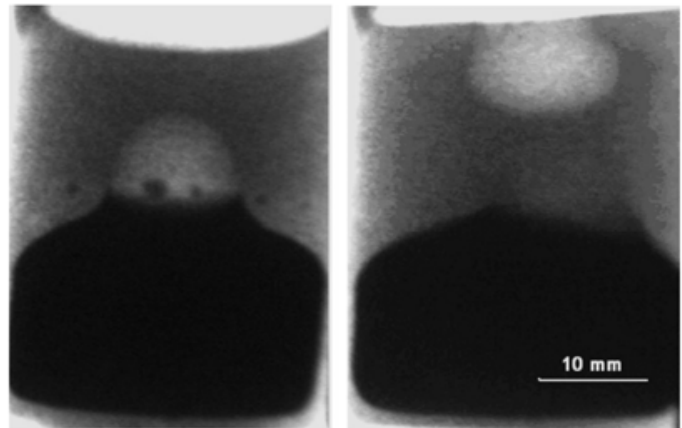

(b)
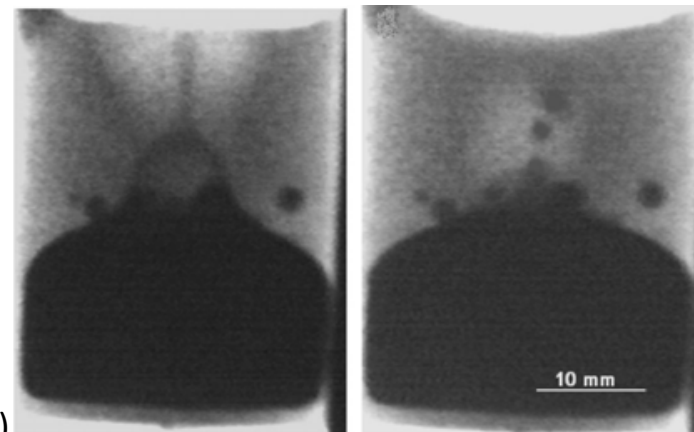
the mechanism of iron droplet entrainment into slag 

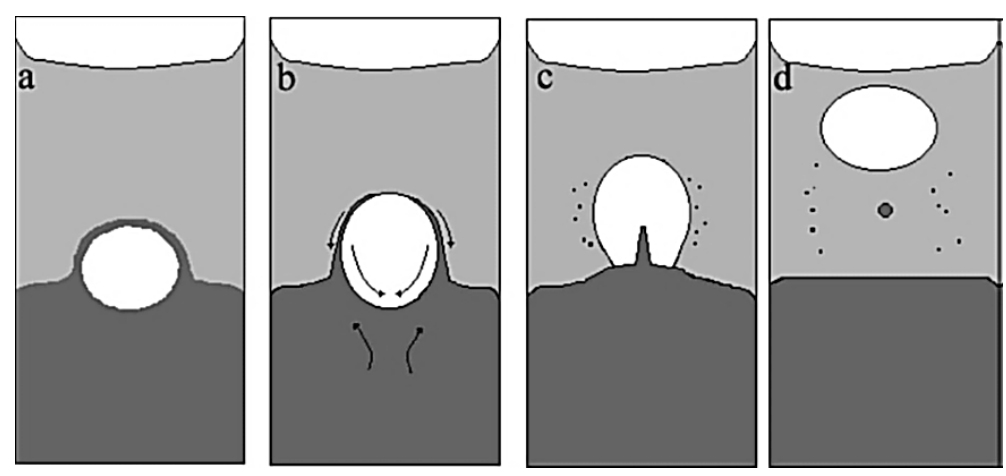

Fig. 9 Proposed mechanisms for the formation of jet and film droplets in the slag when a gas bubble passes through the iron/slag interface [57] 


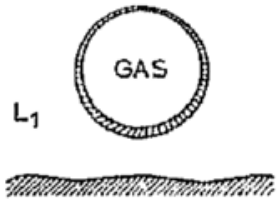

$\mathrm{L}_{2}$

(a)

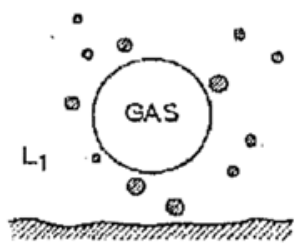

$L_{2}$

(b)

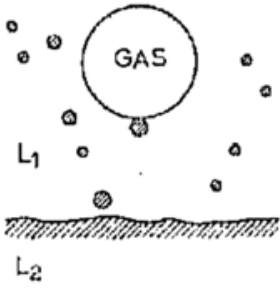

(c)

Fig. 10 Interactions between a gas bubble and liquid droplets in a continuous phase: $(a)$ a film of the underlying phase $\left(L_{2}\right)$ is formed on the gas bubble, (b) droplets of the underlying phase (L2) are scattered in the upper liquid $\left(L_{1}\right)$, and (c) attachment of the droplets of the underlying phase $\left(L_{2}\right)$ to the bubble through contact [59] 


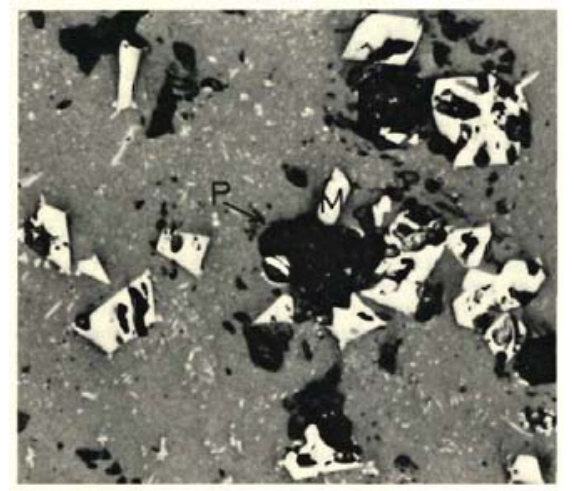

Fig. 11 Slag with 3.8 wt\% lead: (M) Magnetite, (P) metallic lead (magnification x400) [4] 

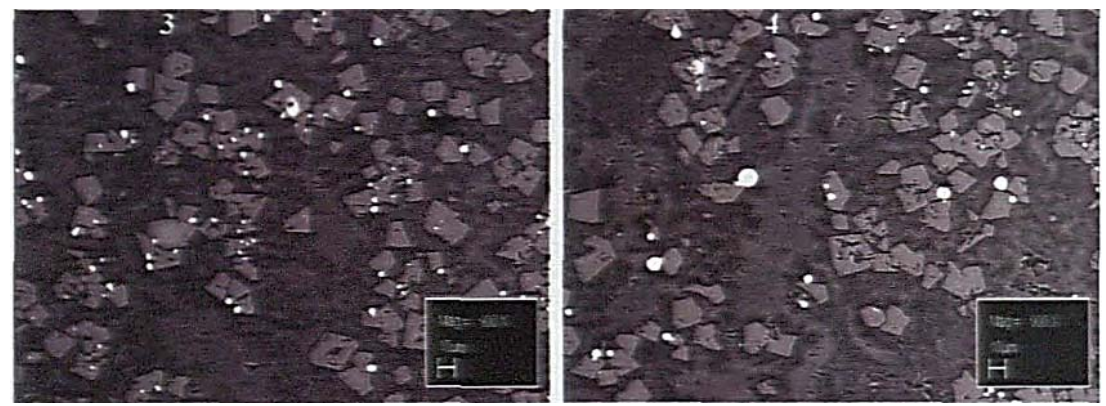

Fig. 12 SEM backscattered electron images of slag containing metallic droplets [6] (the scale bar in the figure represents 10 $\mu \mathrm{m})$ 

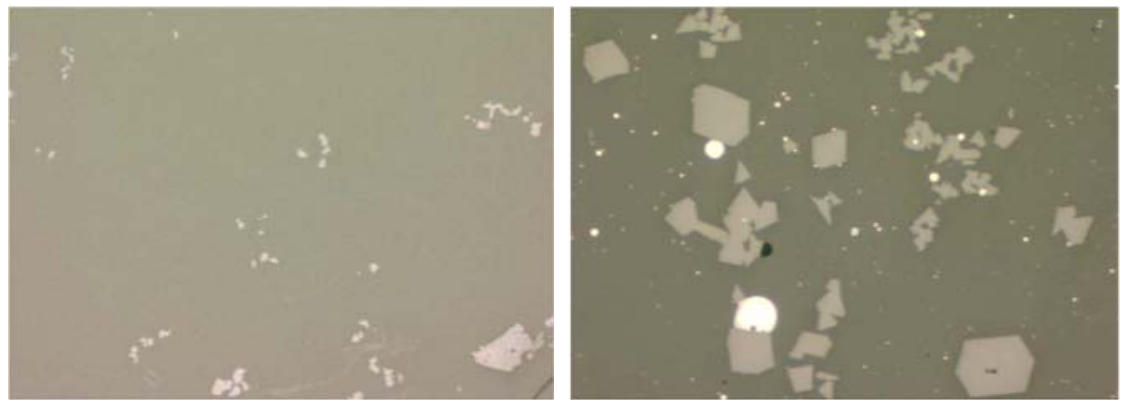

Fig. 13 Left: slag at $1200^{\circ} \mathrm{C}$ contains $2 \%$ spinels (with Fe and $\mathrm{Zn}$ ); Right: slag at $1140^{\circ} \mathrm{C}$ contains $10 \%$ spinels which entrain some $\mathrm{Cu}$ drops [63] 
(a)

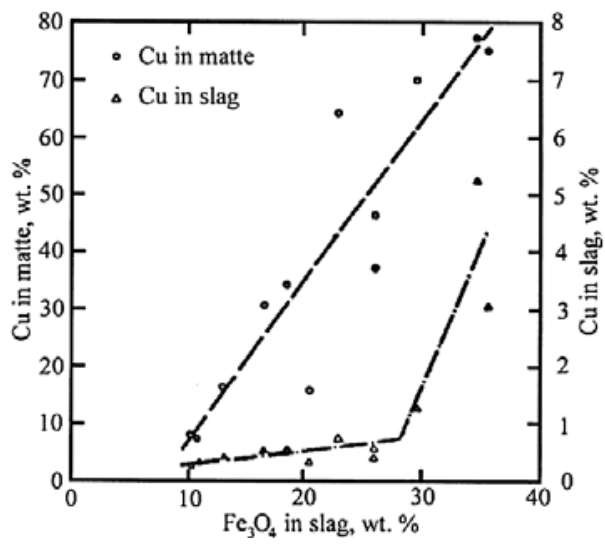

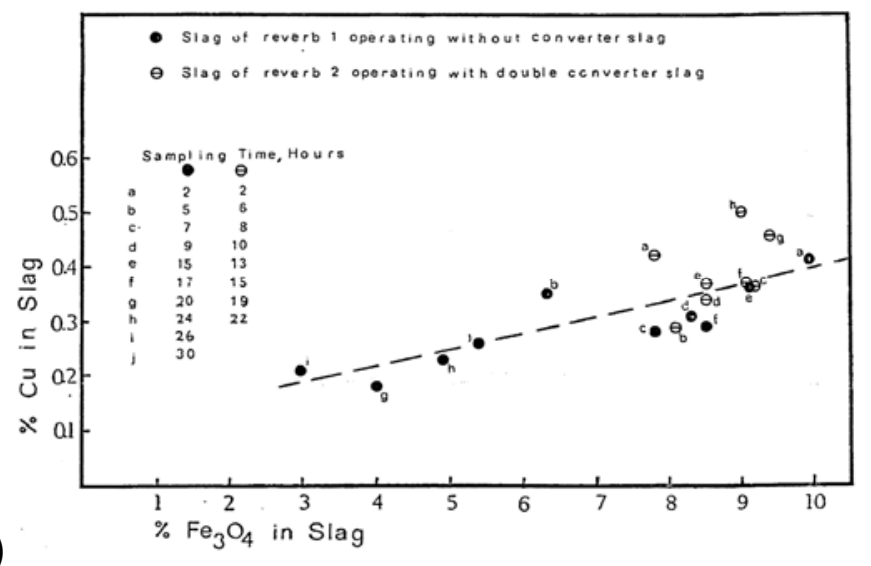

(b)

Fig. 14 (a) Copper content in slag and matte versus magnetite content in slag at $1250^{\circ} \mathrm{C}$. [25] (b) Special 24 hour industrial test in la Oroya smelter $[3,64]$ 

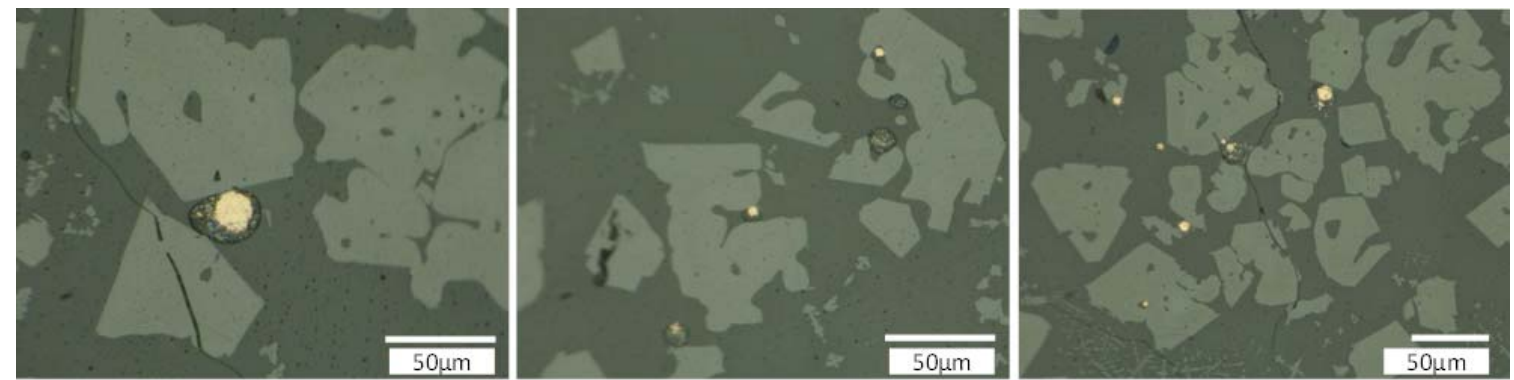

Fig. 15 Detailed microstructures (LOM) of sticking droplets (Cu-Pb) onto (Fe- $\mathrm{Zn}-\mathrm{Al}-\mathrm{O})$ spinel particles present in slag obtained by melting a mixture of 1.4wt\% $\mathrm{Al}_{2} \mathrm{O}_{3}-2 \mathrm{wt} \% \mathrm{CaO}-17.2 \mathrm{wt} \%$ FeO-45.6wt\% PbO-8.4wt\% $\mathrm{ZnO}-10.1 \mathrm{wt} \% \mathrm{Cu}-15.2 \mathrm{wt} \%$ $\mathrm{SiO}_{2}$ at $1200^{\circ} \mathrm{C}$ under a $\mathrm{p}_{02}$ of $10^{-7} \mathrm{~atm}$. [61] 
$5 \mathrm{~min}$

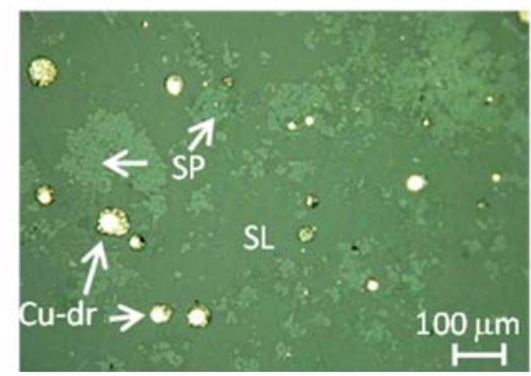

$30 \mathrm{~min}$

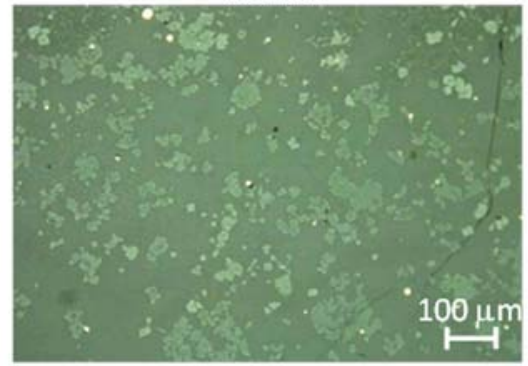

$10 \mathrm{~min}$

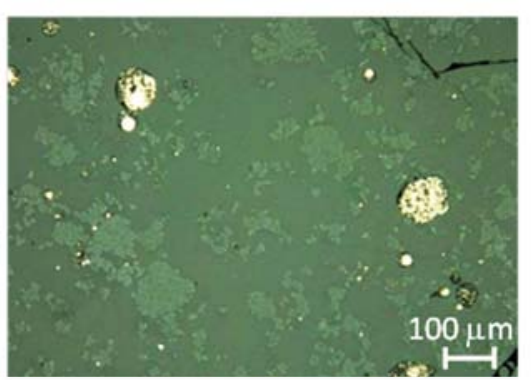

$60 \mathrm{~min}$

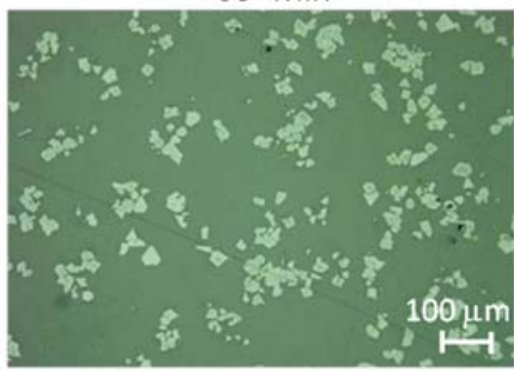

$20 \mathrm{~min}$

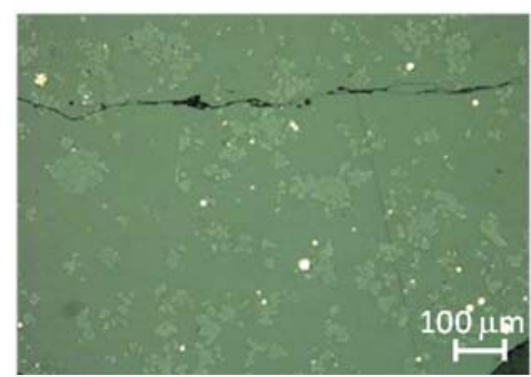

$90 \mathrm{~min}$

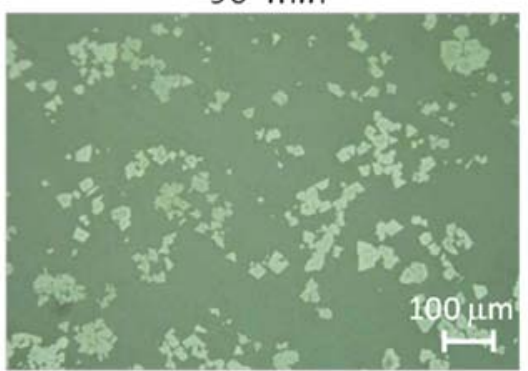

Fig. 16 Representative LOM pictures of the upper slag layer at 5, 10, 20, 30, 60 and 90 min after bubbling in slag obtained by melting a mixture of 7.3wt\% $\mathrm{Al}_{2} \mathrm{O}_{3}-9.8 w t \% \mathrm{CaO}-19.4 \mathrm{wt} \%$ FeO-39.3wt\% $\mathrm{PbO}-6.5 \mathrm{wt} \% \mathrm{ZnO}-3.9 \mathrm{wt} \% \mathrm{Cu}-13.8 \mathrm{wt} \% \mathrm{SiO}_{2}$ at $1200^{\circ} \mathrm{C}$ under a po2 of $10^{-7} \mathrm{~atm}$. (SL = slag, SP = Al-Fe-Zn-O spinel solids, Cu-dr = copper-lead alloy droplets) [62] 


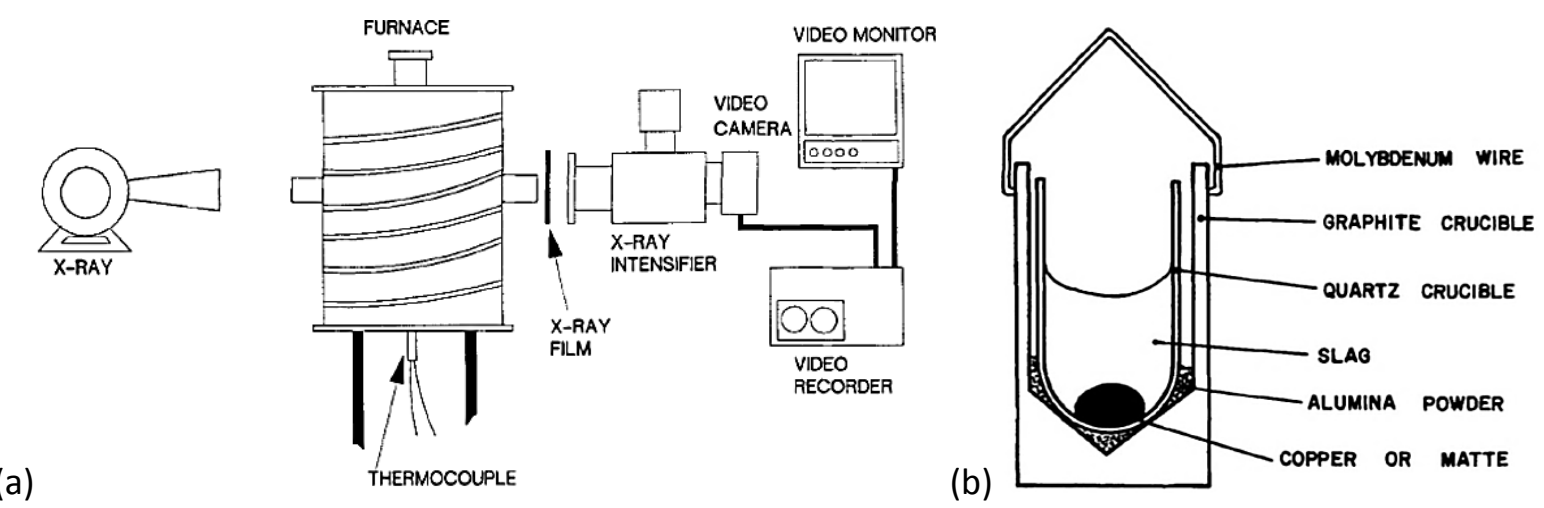

(a)
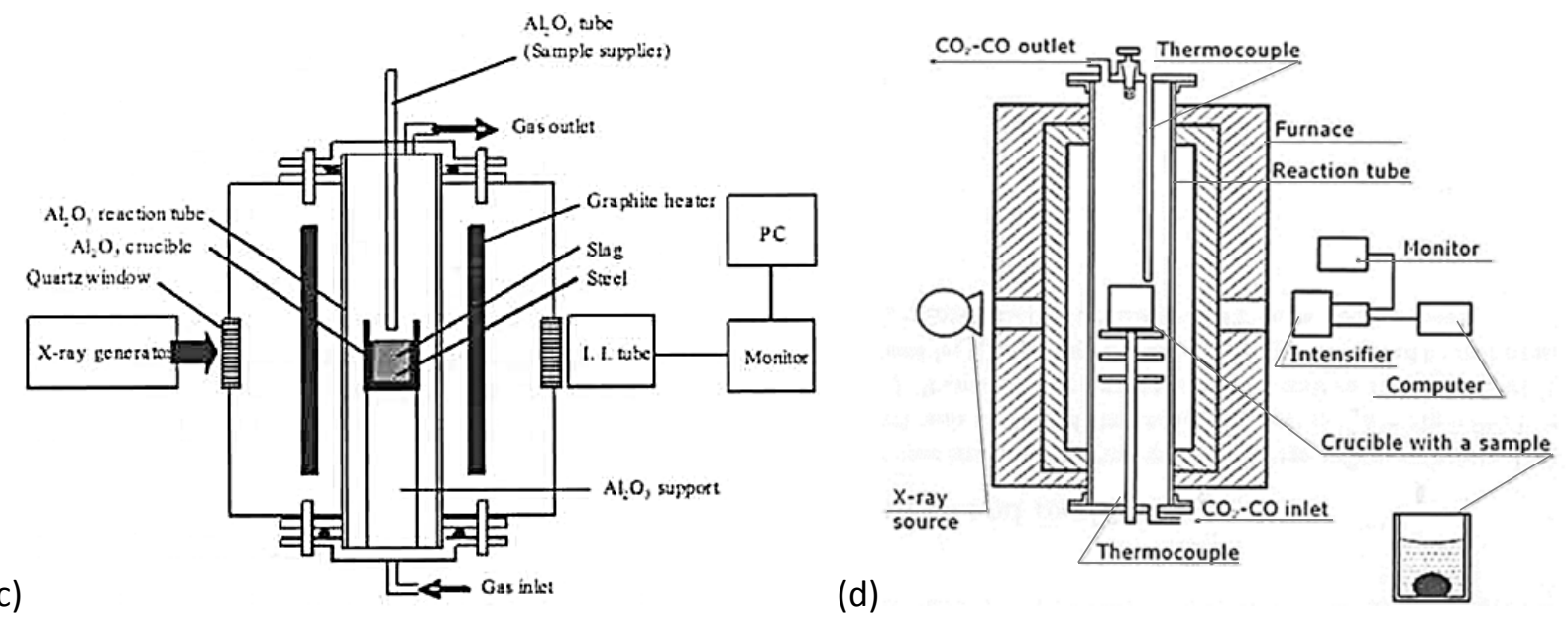

Fig. 17 (a) X-ray set-up by Ip and Toguri [50] for high-temperature interfacial tension measurements; (b) sample arrangement for interfacial tension measurements in the X-ray set-up of Ip and Toguri [50]; (c) Schematic illustration of X-ray set-up used by Matsushita et al. [79]; (d) Apparatus used by Rogóż et al. [80] for the measurements of the interfacial surface tension in the metal/slag system 